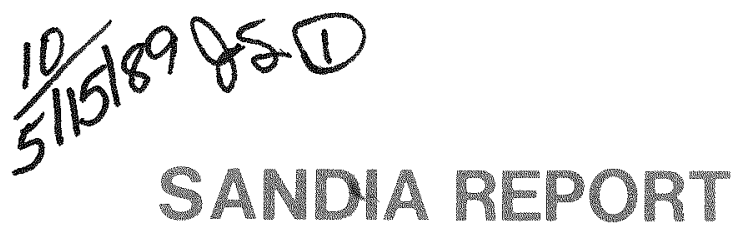

SAND89-0710 U UC-132

Unlimited Release

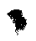

Printed April 1989

\title{
Core Analysis in a Low Permeability Sandstone Reservoir: Results From the Multiwell Experiment
}

Allan R. Sattler

\section{Prepared by}

Sandia National Laboratories

Albuquerque, New Mexico 87185 and Livermore, California 94550

for the United States Department of Energy

under Contract DE-AC04-76DP00789

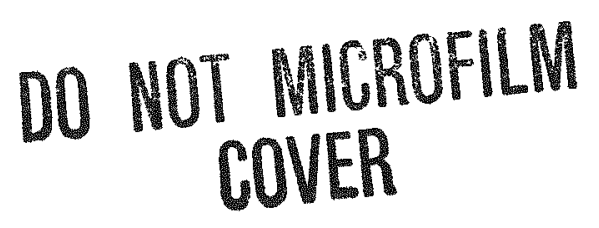


Issued by Sandia National Laboratories, operated for the United States Department of Energy by Sandia Corporation.

NOTICE: This report was prepared as an account of work sponsored by an agency of the United States Government. Neither the United States Government nor any agency thereof, nor any of their employees, nor any of their contractors, subcontractors, or their employees, makes any warranty, express or implied, or assumes any legal liability or responsibility for the accuracy, completeness, or usefulness of any information, apparatus, product or process disclosed, or represents that its use would not infringe privately owned rights. Reference herein to any specific commercial product, process, or service by trade name, trademark, manufacturer, or otherwise, does not necessarily constitute or imply its endorsement, recommendation, or favoring by the United States Government, any agency thereof or any of their contractors or subcontractors. The views and opinions expressed herein do not necessarily state or reflect those of the United States Government, any agency thereof or any of their contractors.

Printed in the United States of America. 'This report has been reproduced directly from the best available copy.

Available to DOE and DOE contractors from

Office of Scientific and Technical Information

PO Box 62

Oak Ridge, TN 37831

Prices available from (615) 576-8401, FTS 626-8401

Available to the public from

National Technical Information Service

US Department of Commerce

5285 Port Royal Rd

Springfield, VA 22161

NTIS price codes

Printed copy: A04

Microfiche copy: A01 


\section{DISCLAIMER}

This report was prepared as an account of work sponsored by an agency of the United States Government. Neither the United States Government nor any agency Thereof, nor any of their employees, makes any warranty, express or implied, or assumes any legal liability or responsibility for the accuracy, completeness, or usefulness of any information, apparatus, product, or process disclosed, or represents that its use would not infringe privately owned rights. Reference herein to any specific commercial product, process, or service by trade name, trademark, manufacturer, or otherwise does not necessarily constitute or imply its endorsement, recommendation, or favoring by the United States Government or any agency thereof. The views and opinions of authors expressed herein do not necessarily state or reflect those of the United States Government or any agency thereof. 


\section{DISCLAIMER}

Portions of this document may be illegible in electronic image products. Images are produced from the best available original document. 
DE89 011320

SAND - -89-0710

CORE ANALYSIS IN A LOW PERMEABILITY SANDSTONE RESERVOIR: RESULTS FROM THE MULTIWELL EXPERIMENT

by

ALIAN R. SATTLER

Geotechnology Research

Division 6253

Sandia National Laboratories

Albuquerque, NM 87185

Printed April, 1989

\begin{abstract}
Over $4100 \mathrm{ft}$ (1100 ft oriented) of Mesaverde core was taken during the drilling of the three Multiwell Experiment (MWX) wells, for study in a comprehensive core analysis program. This core traversed five separate depositional environments (shoreline/marine, coastal, paludal, fluvial, and paralic), and almost every major sand in the Mesaverde at the site was sampled. This paper summarizes MWX core analysis and describes the petrophysical properties at the MWX site; reservoir parameters, including permeabilities of naturally fractured core; and mechanical rock properties including stress-related measurements. Some correlations are made between reservoix properties and mineralogy/petrology data. Comparisons are made between the properties of lenticular and blanket sandstone morphologies existing at the site. This paper provides an overview of a complete core analysis in a low-permeability sandstone reservoir.
\end{abstract}


I thank N. R. Warpinski for many discussions and suggestions, especially about mechanical rock properties. J. C. Lorenz and S. J. Finley are acknowledged for many discussions about depositional environments and natural fracture systems at the MWX site. D. A. Northrop is thanked for many technical discussions about all aspects of MWX and for suggestions of organization and preparation of this paper. I commend M. L. Brugler, S. H. Leeds, F. J. Duplessis, R. Gallop, J. D. Walls, P. L. Randolph, D. J. Soeder, P. J. Hudson, N. R. Morrow, Jill S. (Ward) Buckley, and P. E. Senseny for their key roles in helping to plan and execute the MWX core analysis, for their interpretations of the data, and for our many detailed discussions about the MWX core data. I thank G. C. Kukal for many discussions about the core analyses and the electrical parameters. The Multiwell Experiment is part of the Western Gas Sands Sub Project managed by K.-H. Frohne at the Morgantown Energy Technology Center under contract number DE-ACC4-76DP00789. 
INTRODUCTION

The U.S. Department of Energy's Multiwell Experiment (MWX) is a research-oriented field laboratory. Its objectives are to thoroughly characterize lenticular tight gas sands occurring in the western United States and to develop technology for their production. Three closely spaced, straight, vertical wells, designated MWX 1, MWX 2, and MWX 3, which are less than $225 \mathrm{ft}$. apart at depth, were drilled through the Mesaverde formation in the Piceance basin near Rifle, Colorado. The Mesaverde formation at the MWX site contains five diverse depositional environments (Figure 1): shoreline/marine, delta plain (lower-paludal and uppercoastal), fluvial, and paralic (Lorenz, 1983, 1986). Most of the shoreline/marine sandstones and shales in the Mesaverde are blanket-1ike in the area of the Piceance basin around the MWX site. This is in contrast to the more heterogeneous strata including the lenticular sandstones, those of the paludal, coastal, and fluvial zones. The paralic formation shows signs of marine influence. Because of high water saturations, the paralic zone is thought to contain little produceable gas. Our estimates of the gas in place at the MWX site are:

\begin{tabular}{|c|c|}
\hline Zone & $\mathrm{BCF} / \mathrm{mi}^{2}$ \\
\hline marine & 35 \\
\hline paludal & 35 \\
\hline coastal & 31 \\
\hline fluvial & 55 \\
\hline
\end{tabular}

The objectives of this paper are to summarize and to interpret MWX core analysis. This paper constitutes an overview of a complete core analysis in a low-permeability sandstone reservoir. Results from the core program provided inputs for well test and stimulation activities, for information of the earth stresses, and for data to correlate with $10 \mathrm{~g}$ studies to improve their reliability in tight sands. These results also provided a thorough characterization of the Mesaverde formation because core was taken from all depositional environments. The primary efforts of 


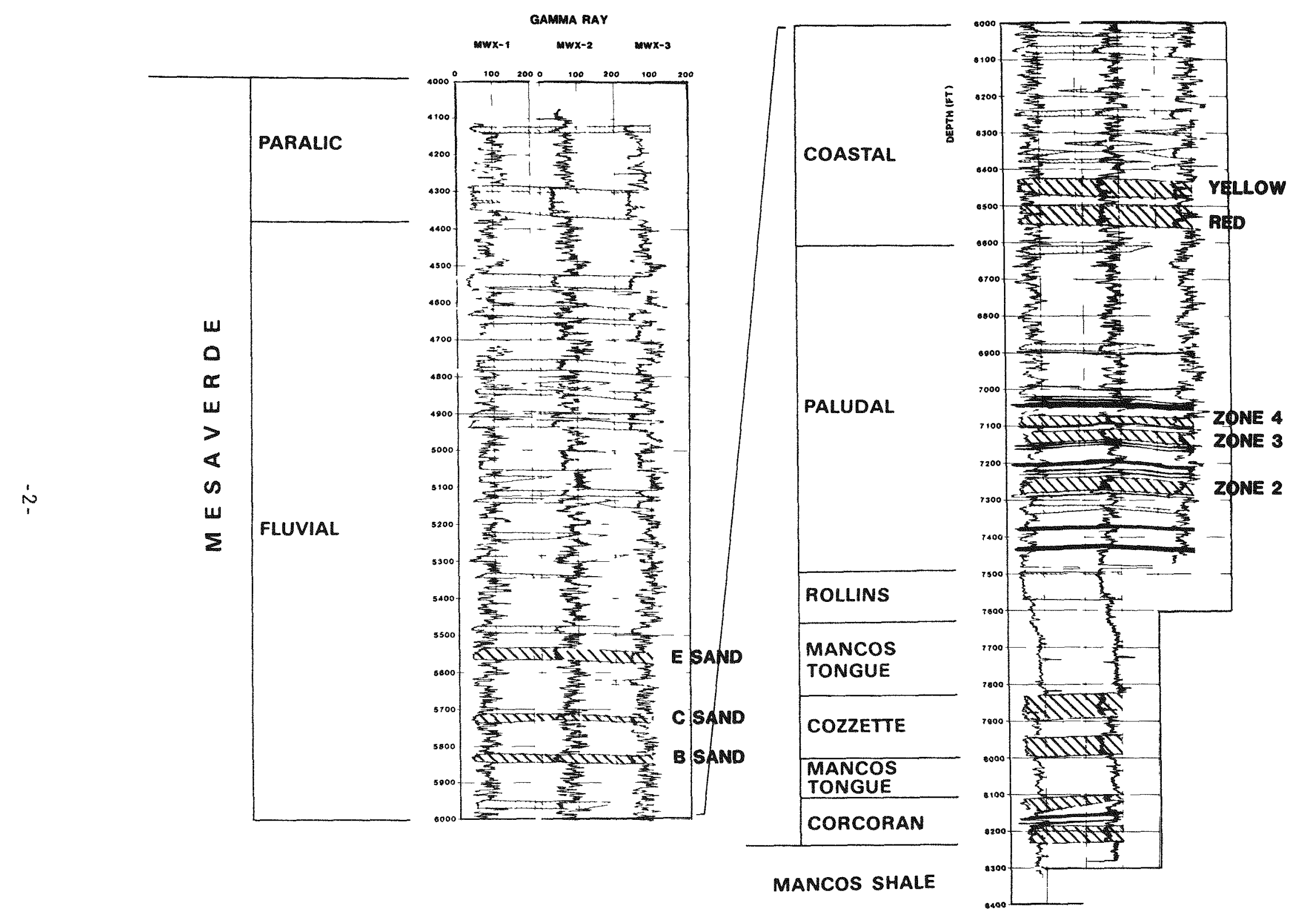

Figure 1. The Mesaverde Formation at the MWX Site. 
the MWX centered in the lenticular sands. Comparisons are made between the core properties of heterogeneous strata that incorporate lenticular sandstones and those of the more uniform blanket formations occurring at the bottom of the Mesaverde formation (Figure 1).

Core analysis is discussed in terms of the existing depositional environments. Sedimentology/depositional environments and mineralogy/ petrology data themselves are not emphasized in this paper. This was published elsewhere (Lorenz, June 1983, 1987; Bendix 1982 to 1984; and Pitman and Spencer, 1984; Sandia/CER MWX Final Report Series, I to IV). Further, correlations are frequently made between core reservoir properties and the mineralogy/petrology data.

Production tests were conducted in MWX 1 in the Corcoran and Cozzette sands, in paludal zone 2 , and the coastal red sand (Figure 1 ). Production tests and stimulations were conducted in MWX 1 in paludal zone 3 and 4 (combined), the coastal yellow sand, and the fluvial $\mathrm{B}, \mathrm{C}$, and $\mathrm{E}$ sands (Branagan, 1984, 1985, 1987; Warpinski, Dec 1987; Sandia/CER MWX Final Report Series I to IV). Emphasis was on the particular sands tested, although core measurements were made throughout the entire Mesaverde column. Data from al1 depositional environments are presented. The sandstones chosen as the focus for this paper are the upper Corcoran (MWX 2), upper Cozzette (MWX 1 and MWX 2), paludal zone 3 (MWX 2), coastal yellow, fluvial B and E and paralic, MWX 1. Geologic features of these sandstones are shown in Table $I$.

\section{CORE PROGRAM}

Over $4100 \mathrm{ft}$ of 4-inch-dia core was taken during the drilling of these three wells (Figure 2). About $1150 \mathrm{ft}$ of the core was oriented. MWX 1 was cored continuously from $4170 \mathrm{ft}$ above the paralic zone to just below the top of paludal zone at $6830 \mathrm{ft}$. Some core was also taken from the Cozzette sand. Only selected intervals were cored in the other two wells. Among the three wells, almost every major sand in the Mesaverde formation at the MWX site was cored. 


\begin{tabular}{|c|c|c|}
\hline $\begin{array}{c}\text { Sand/Depositional } \\
\text { Environmental }\end{array}$ & $\begin{array}{l}\text { (Well) } \\
\text { (Depth, ft) }\end{array}$ & Description \\
\hline
\end{tabular}

Upper Corcoran, Marine/Shoreline

Upper Cozzette, Marine/Shoreline

Paludal zone 3

Coastal yellow

Fluvial B

Fluvial E sand $(5532-5565)$

Paralic sand
Considered a blanket sandstone in the Mesaverde in the region near the MWX

site, but at the MWX site itself, a discontinuous channel sandstone (Lorenz, 1987 ).

(1 or 2) A blanket sandstone near the MWX site, and at the MWX site itself, displays good

(7831-7894) shallow marine/shoreline characteristics. Upper portion of the sand contains a bitumen zone (Lorenz, 1987).

(2) A channel sandstone that shows a good sequence of crossbedded and rippled sands, $(7118-7140)$ with few mudstones. Estimated to be around $350 \mathrm{ft}$ wide (Lorenz, 1983 ).

A composite channel sand separated by $3-4 \mathrm{ft}$ of mudstone. Minimum widths of the two channel sands estimated to be 200-300 ft (Lorenz, 1984).

A meander-belt sandstone composed of point bars. Appears to be one of the more uniform of the fluvial sands at the MWX site, but it is really heterogeneous in detail. Estimated minimum meander-belt width around $1000 \mathrm{ft}$ (Lorenz, 1986 ). Relatively few fractures were seen in this sandstone, but this and the $E$ sand is in a highly fractured portion of the Mesaverde at the MWX site (Finley, Sep. 1986).

A composite sandstone. Upper part is a meander-belt sandstone with a fining upward trend. Lower part is a meander-belt width is about $1800 \mathrm{ft}$ (Lorenz, 1986). Upper part is a splay-type deposit a few hundred feet wide. Three fracture sets were seen in this sandstone (Finley, January 1986.).

A marine-influenced blanket-1ike sandstone (Lorenz, 1987). Paralic zone, which has high water saturation at site, is not well studied. 


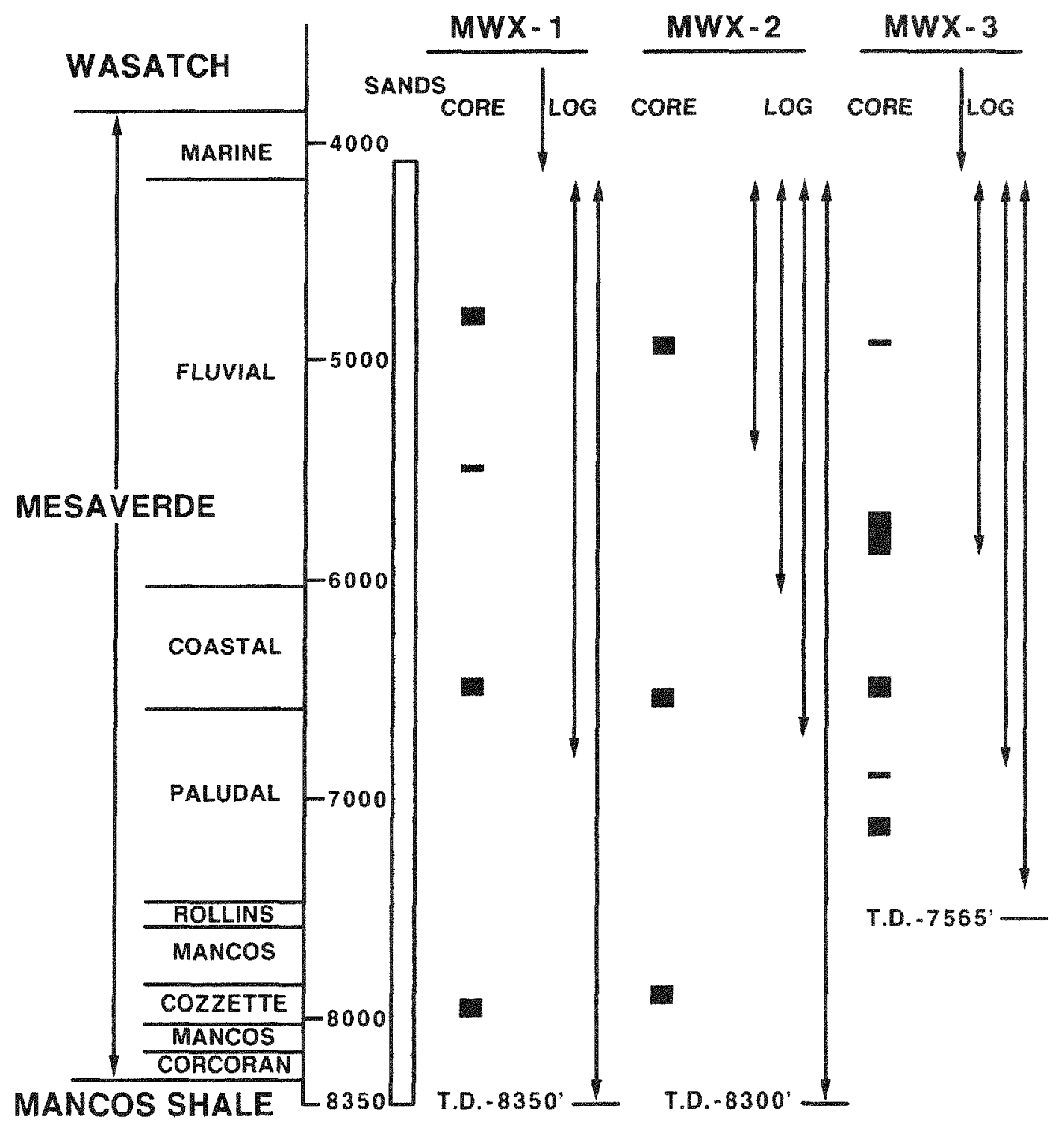

Figure 2. Coring and Logging Intervals at the MWX Site 
Two earlier papers were written about the MWX core program (Sattler, 1983, 1984). Detailed presentations of the core data by depositional environment are to be found in the Sandia/CER MWX Final Report Series, I to IV.

The MWX core program includes the following analyses:

- Routine screening. Routine reservoir parameter core analysis (porosities, water saturations), along with the data from the openhole logs, to determine which regions of the core body require special study.

- Special reservoir parameter core analyses. These include restoredpressure-state permeabilities, pressure core, capillary pressures, caprock analyses, electrical properties, and permeabilities of naturally fractured core.

- Mechanical rock properties. These include Young's modulus, compressive strengths, Poisson's ratio, and fracture toughness. They also includes the correlation of these properties with the core gamma and sonic logs, and stress related core measurements such as anelastic strain recovery (ASR) and differential strain curve analysis (DSCA).

Core plugs were taken for routine core analyses every foot across sand lenses and a few feet into the rock abutting the sands. Over 1500 core plugs were taken. About 500 of them were reused for additional special core analyses. Much of the routine and special core analysis was performed on plugs. This allowed most of the whole core to be available for studies of sedimentology and depositional environments, mechanical rock properties, and natural fractures. After examination of the routine core analysis data, restored state permeability and cation exchange capacity (CEC) measurements were made every 1 to $3 \mathrm{ft}$ using many of the same plugs. These two successive stages of core analysis provided much of the necessary reservoir data across a sand lens. 
Thin-sections were taken subsequently by facing off the ends of these same core plugs. Preference for thin-section analyses was given to the plug ends corresponding to the plugs selected for measurements of restoredstate permeabilities. This allowed correlations between sandstone reservoir properties and mineralogy/petrology data. It is necessary to make correlations from the same interval because properties can often vary rapidly in a lenticular sequence.

The more time-consuming and expensive core analyses were conducted at less frequent intervals. These analyses included determining mechanical rock properties, capillary pressure, relative permeabilities, specific permeabilities to brine, formation factors, and resistivity indexes. Samples for these further studies were chosen after examining routine core analysis and restored state permeability measurements.

There is interest not only in the sandstone lenses and the reservoir rock, but also in the rock abutting the sand (usually siltstones, mudstones, and shales). Mechanical rock properties of these abutting formations (and those of the sandstone reservoir) are inputs for hydraulic fracture containment analyses. Caprock analyses provide some idea about the extent of the reservoir and indicate how adequate these abutting formations are as stratigraphic barriers between sandstone units. CEC measurements, in addition to being used with the electrical measurements, in the Archie, Waxman, Smits formalisms (Waxman and Smits, 1968, Waxman and Thomas, 1974), allow an approximate, rapid estimate of clay between the sand and the formations abutting the sand. These measurements also give an indication of how shaly the abutting formations are. Very limited analysis of mineralogy was done on the rock abutting the sandstones (Dowe11 Schlumberger, August 1985).

CORE HANDLING

Special core-processing and storage facilities were constructed near the MWX site. The core-processing facility was set up in a building at 
Department of Energy's Anvil Points complex across the Colorado River and about $15 \mathrm{mi}$ by road from the MWX site.

When the core came to the surface, it was removed from the core barrel by project geologists and placed in trays. After a quick preliminary inspection and removal of samples for special measurements, such as ASR, the core was covered with plastic to prevent evaporation and then with thick canvas to protect it from the elements. The core was then transported to Anvil Points for processing. Field processing of the core entailed many nonstandard core-processing procedures that included the following:

- (Construction and) use of a six-detector core gamma assembly. The core gamma assembly provided for well control during drilling and for core $\log$ depth correlation after logging. The core gamma assembly also has better spatial resolution than the open-hole gamma-ray $\log$.

- Marking the positions and magnitude of scribe-line deviation and locations of connections and other breaks in core.

- Photographing the entire amount of core in color.

- Taking of core plugs.

- Preserving core.

- Making a visual core log followed by construction of a detailed lithology/sedimentology log from slabbed core.

- Using special no-freeze freight service in the winter to ship samples selected for measurements of reservoir parameter or mechanical rock properties. 
MWX used a dedicated core library, constructed at the DOE/Grand Junction facility, from 1981 through 1986. This facility is about $60 \mathrm{mi}$ from the MWX site. From mid-1986 to the present, the core facility has been located at Sandia National Laboratories in Albuquerque, New Mexico.

\section{ROUTINE CORE ANALYSES}

Routine core analysis was performed on all the plugs taken (Core Laboratories Routine Core Analyses Reports, 1981, 1982, 1983). The routine core analyses included water saturation and porosity (Table II). Porosities of sands were usually in range of 5 to 10 percent and do not exceed 15 percent. Water saturations averaged around 65 percent at the top of the Mesaverde and 30 to 35 percent in some of the productive sands.

Table II

Routine Core Analysis

\begin{tabular}{|c|c|c|c|}
\hline Sand & $\phi(8)$ & $S_{w}(8)$ & Comments \\
\hline Corcoran, MWX 2 & 5.0 & -49 & $\phi, \mathrm{S}_{\mathrm{w}}$ tend to be uniform over sand. \\
\hline $\begin{array}{l}\text { Upper Cozzette, MWX 1,2 } \\
\text { (Production zone) }\end{array}$ & 7.3 & $\begin{array}{l}-36 \\
-79\end{array}$ & $\phi, \mathrm{S}_{\mathrm{w}}$ uniform vertically and \\
\hline (Bitumen zone) & 3.2 & -79 & $\phi, \mathrm{S}_{\mathrm{w}}$ uniform across zone. \\
\hline Paludal zone 3, MWX 2 & 10.5 & $\sim 27$ & $\begin{array}{l}\phi, S_{w} \text { uniform across lens center. } \\
\phi \text { lower, } S_{w} \text { higher, at edges of lens. }\end{array}$ \\
\hline Coastal yellow, MWX 1 & 7.0 & -38 & $\begin{array}{l}\phi, S_{w} \text { uniform across lens center. } \\
\phi \text { lower, } S_{w} \text { higher, at edges of lens. }\end{array}$ \\
\hline Fluvial B, MWX 1 & 6.7 & -46 & $\phi$ lower, $S_{w}$ higher, at edges of lens. \\
\hline Fluvial E, MWX 1 & 5.0 & -60 & $\begin{array}{l}\text { Sand Fines Upward. } \\
\phi \text { high, } S_{w} \text { low at bottom of lens. } \\
\phi \text { low, } S_{w} \text { high at top of lens. }\end{array}$ \\
\hline Paralic, MWX 1 & 5.5 & -65 & $\phi, S_{w}$ fairly uniform. \\
\hline
\end{tabular}


An accurate determination of water saturation is important because permeability depends strongly upon water saturation. At realistic confining pressures, permeabilities of dry core and core at realistic water saturations can differ by two orders of magnitude.

The drilling and coring of the MWX wells was usually done "at or near balanced" conditions which means that the weight of the column of drilling fluid is about the same as formation gas pressure. This balance would minimize invasion of the core and formation by drilling fluid. Oil-based drilling fluid was used in the drilling of MWX 1 and MWX 2, in part to further prevent invasion of core and formation by water-based drilling fluids. These steps would result in more accurate water saturation values. (However after subsequent determination of reservoir pressures it appeared that the mud weights were a few hundred psi lower than the measured reservoir pressure.)

Water-based drilling fluid was used in MWX 3 so that a more thorough suite of electric logs could be run. An ammonium nitrate tag was used in the drilling of MWX 3 to try to differentiate the water saturations from invasion fluids. Differences in nitrate concentrations reported by the mud logger and Core Laboratories, plus the rapid variation of properties in these sandstone lenses over short distances, made a determination of correction factors impossible (Core Labs Report, P83012, 1984). Each saturation value of the MWX 3 plugs (Core Labs Routine Analysis Report, 1983) may be 5 percent to 15 percent (of porosity) high because of invasion in MWX 3.

Water saturation values were determined by the Dean Stark method in the core from MWX 1 and MWX 2 and by the summation of fluids method in the core from MWX 3. We chose the 1atter method because MWX pressure core data suggested that the Dean Stark method may not be the most efficient way of extracting water from tight sandstone core (see the Pressure Core section, Sattler, 1984). 
Boyle's law porosity measurements were made on the core plugs with helium because equilibration of the helium pressure in these tight sands would occur faster with a core plug than with whole core. During determination of the porosity, additional equilibration time was allowed.

The porosity of MWX core seems to change very little with confining pressure (Table III) (Core Labs SCAL Reports, March 82, February 83, June $24,83)$. This is unlike the dependence of permeability on confining pressure (see Special Core Analysis).

Table III

Porosity (8) as a Function of Confining Pressure

\begin{tabular}{|c|c|c|c|c|c|}
\hline \multirow[b]{2}{*}{ Depth ( $f t)$} & \multicolumn{5}{|c|}{ Overburden Pressure (psi) } \\
\hline & 200 & 1000 & 2000 & 3000 & 200 \\
\hline \multicolumn{6}{|c|}{ Corcoran, MWX 2} \\
\hline 8117 & 7.2 & 7.0 & 7.0 & 6.8 & \\
\hline \multicolumn{6}{|c|}{ Cozzette, MWX 2} \\
\hline 7885 & 8.2 & 8.0 & 8.0 & 7.9 & \\
\hline 7864 & 7.2 & 7.0 & 7.0 & 6.8 & \\
\hline \multicolumn{6}{|c|}{ Paludal, MWX 2} \\
\hline 7366 & 11.1 & 11.0 & 11.0 & 11.0 & 11.0 \\
\hline 7121 & 4.1 & 4.0 & 3.9 & 3.8 & 4.0 \\
\hline \multicolumn{6}{|c|}{ Coastal, MWX 1} \\
\hline 6550 & 6.8 & 6.7 & 6.7 & 6.7 & \\
\hline 6537 & 8.2 & 8.0 & 8.0 & 7.9 & \\
\hline \multicolumn{6}{|c|}{ Fluvial, MWX 1} \\
\hline 5730 & 6.1 & 6.0 & 5.9 & 5.9 & 6.1 \\
\hline 5133 & 9.1 & 9.0 & 8.9 & 8.9 & 9.0 \\
\hline
\end{tabular}


Measurements of Dry Restored Pressure State Permeabilities

Dry Klinkenbexg permeability measurements were performed to obtain information of the variation of permeability over a sand lens (Core Labs SCAL Reports, February 1982 to August 1987; Institute of Gas Technology (IGT) Dry Core Reports, July, August, October 1982, June 1984; Wei, 1986). It has been well known for some time that the permeability of these tight sands depends on confining pressure (Jones and Owen, 1980). Apparently, temperature has very little effect on permeability (Wei, 1986).

Dry Klinkenberg permeability range from microdarcies to tens of microdarcies. The average values for the sands studied are summarized in Table IV. Also included in Table IV are measured pore-pressure values and estimated net confining pressures. Vertical permeabilities appear to be about the same as horizontal permeabilities (Core Labs SCAL Reports, February 1982 to August 1987; Wei, 1986).

In the Corcoran sand, the effects of carbonaceous stringers and/or narrow fractures is apparent in Table IV as shown by the higher average dry permeability over that of the matrix rock.

In the lower part of the fluvial zone, there are some narrow, "permeability streaks," where the permeabilities are much larger than in the surrounding sandstone. In some cases these streaks may be continuous between wells. Figure 3 shows one such streak in the $B$ sand. The corresponding thin-section data show a tendency toward low clay content and larger maximum grain sizes (Bendix, October 1982, May 1983, July 1984). Also, there is a greater spread in the proportions of illite and mixed layered clays in the fluvial zone than in the other lenticular zones (New Mexico Petroleum Research Recovery Center (PRRC) 1987). Perhaps these contrasts in amounts of layered clays translate into permeability contrasts. 
Table IV

Estimated Dry and Saturated Klinkenberg Permeability Values and Related Reservoir Characteristics

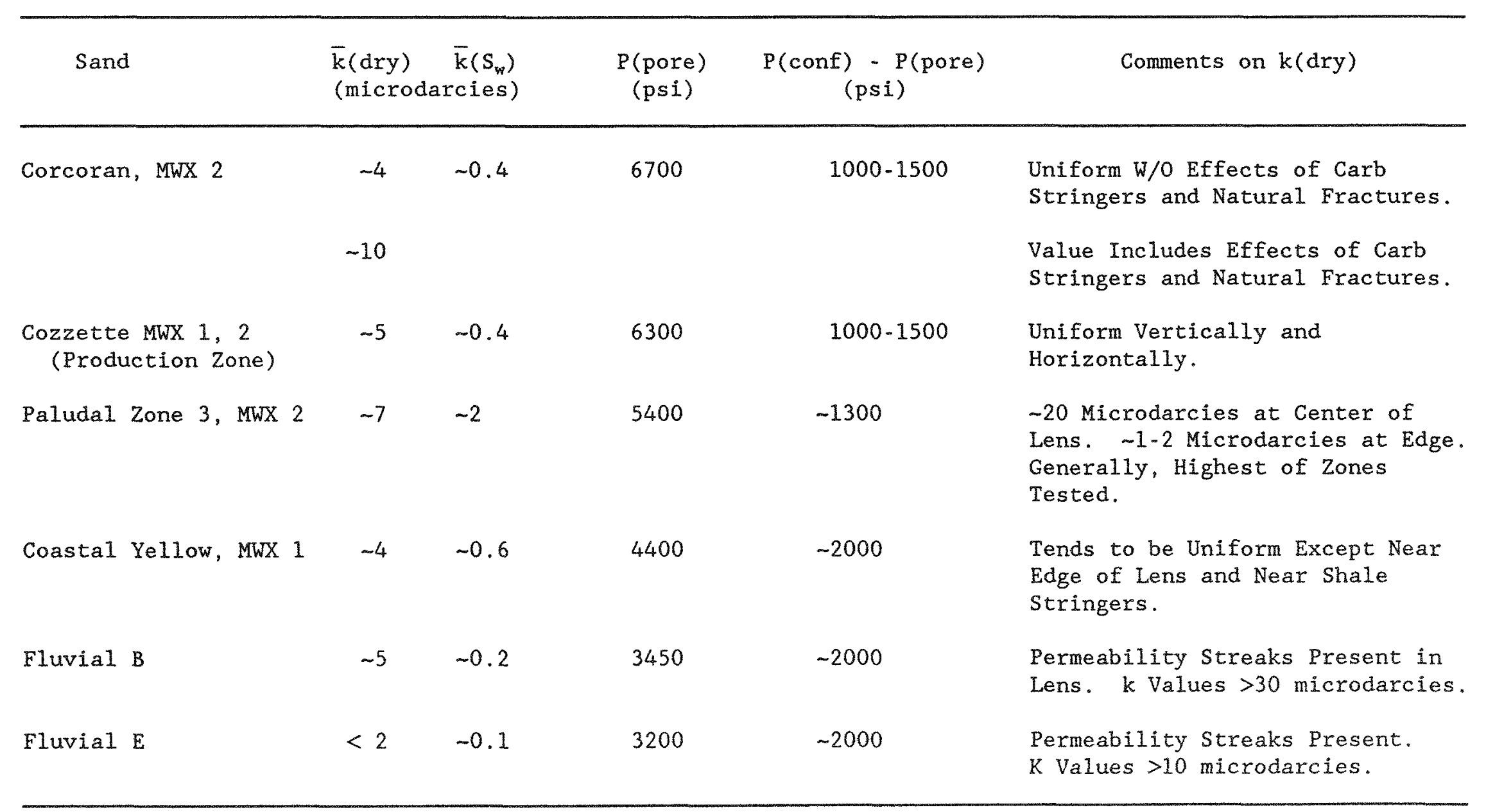




\section{SAND MWX-1}

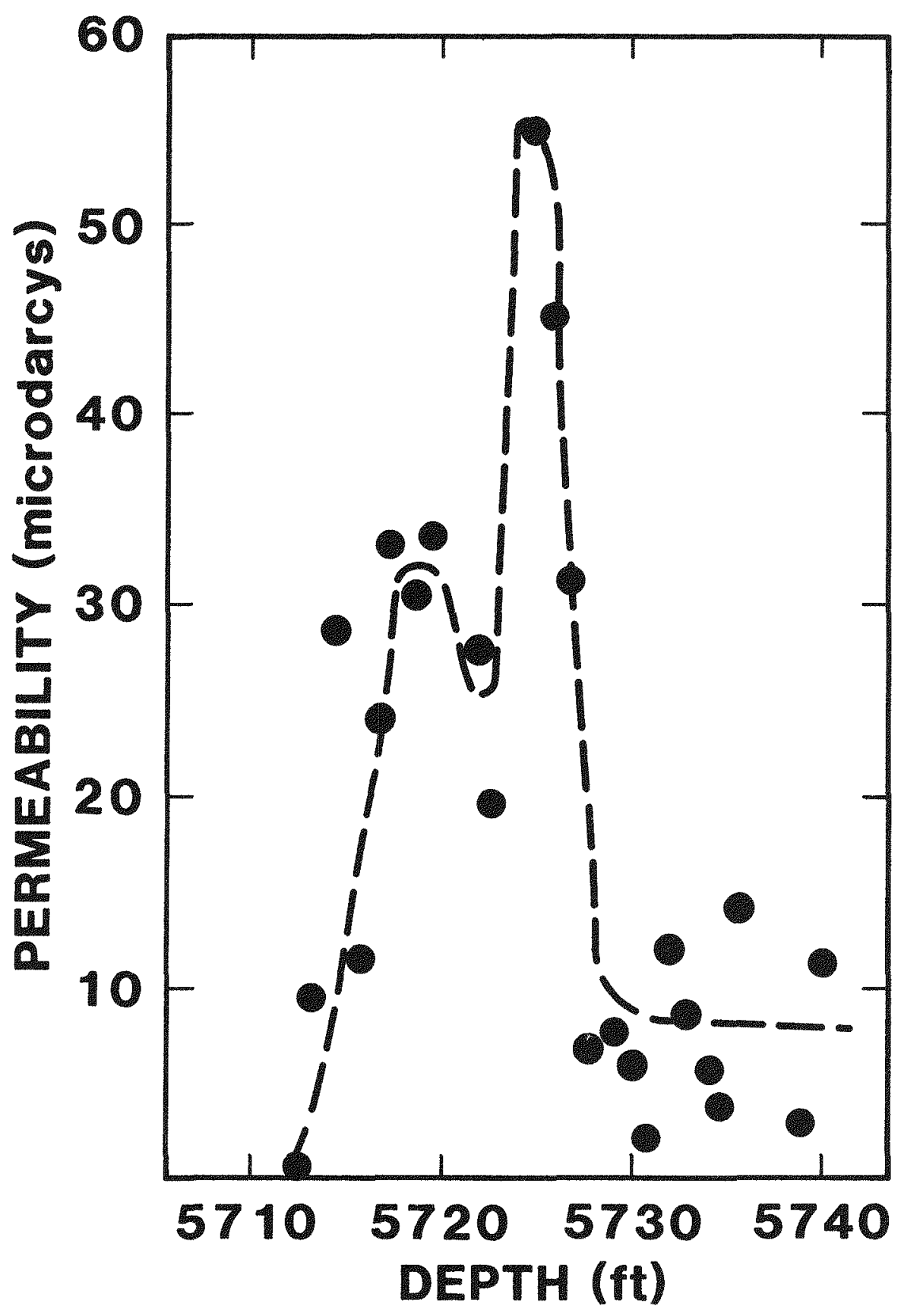

Figure 3. Permeability Streak in Fluvial Zone 
These horizontal permeability streaks would create conduits to a vertical fracture system occurring at the MWX site. The permeability streaks might recharge the natural fracture system during gas production (Figure 4). There appear to be permeability streaks in both the B and E sands.

The permeabilities of the few measured paralic sandstone samples are in the range 70 to 80 microdarcies and these are among the highest values found in the Mesaverde at the MWX site (Core Labs SCAL Report, June 1984). At the top of the Mesaverde (high fluvial/paralic zones), thin-section data indicate relatively coarse-grained sands and well-connected porosity. In one paralic sample where permeability measurements were made (4331.2 ft) the description even suggests primary porosity (Bendix, April, July 1983).

Figure 5 shows the dry Klinkenberg permeabilities as a function of confining pressure for each of two paludal and fluvial samples. The permeability of the fluvial sample decreases about tenfold over a pressure range of 1000 to 7000 psi, whereas the permeability of the paludal samples decreases only twofold over the range. The permeabilities of samples from the paralic and fluvial zones, the coastal zone, the cozzette, and the paludal zone generally seem decreasingly dependent on pressure, in that respective order (using $k_{1000} \mathrm{psi} / \mathrm{k}_{3000} \mathrm{psi}$ ). Their pressure dependence on permeability appears to vary with grain size and the amount of dolomitic cement (Bendix, July 1982, August, December 1982, January, April, May 1983). Large grain sizes and/or relatively small to no amounts of dolomitic cement may imply a larger pressure dependence on permeability. However, there is a large scatter and overlap in these mineralogic parameters from one depositional environment to the next. There may not be any simple correlation of mineral properties. Other authors have discussed this problem (Kilmer, 1987; New Mexico Tech, 1987; IGT, June 1984; Soeder and Randolf, 1987). 


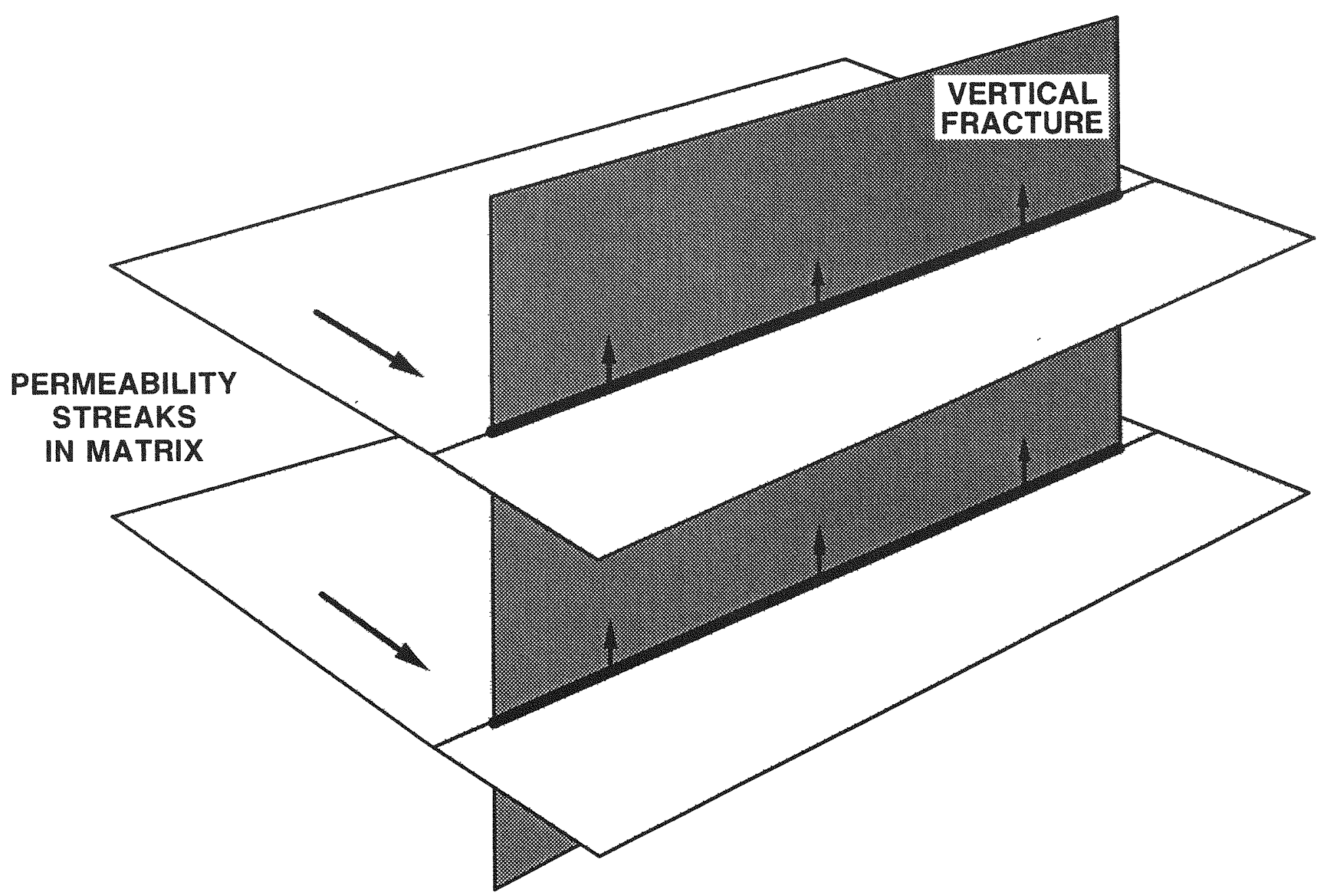

Figure 4. Schematic of Proposed Interaction Between Permeability Streaks and Extension Fractures 


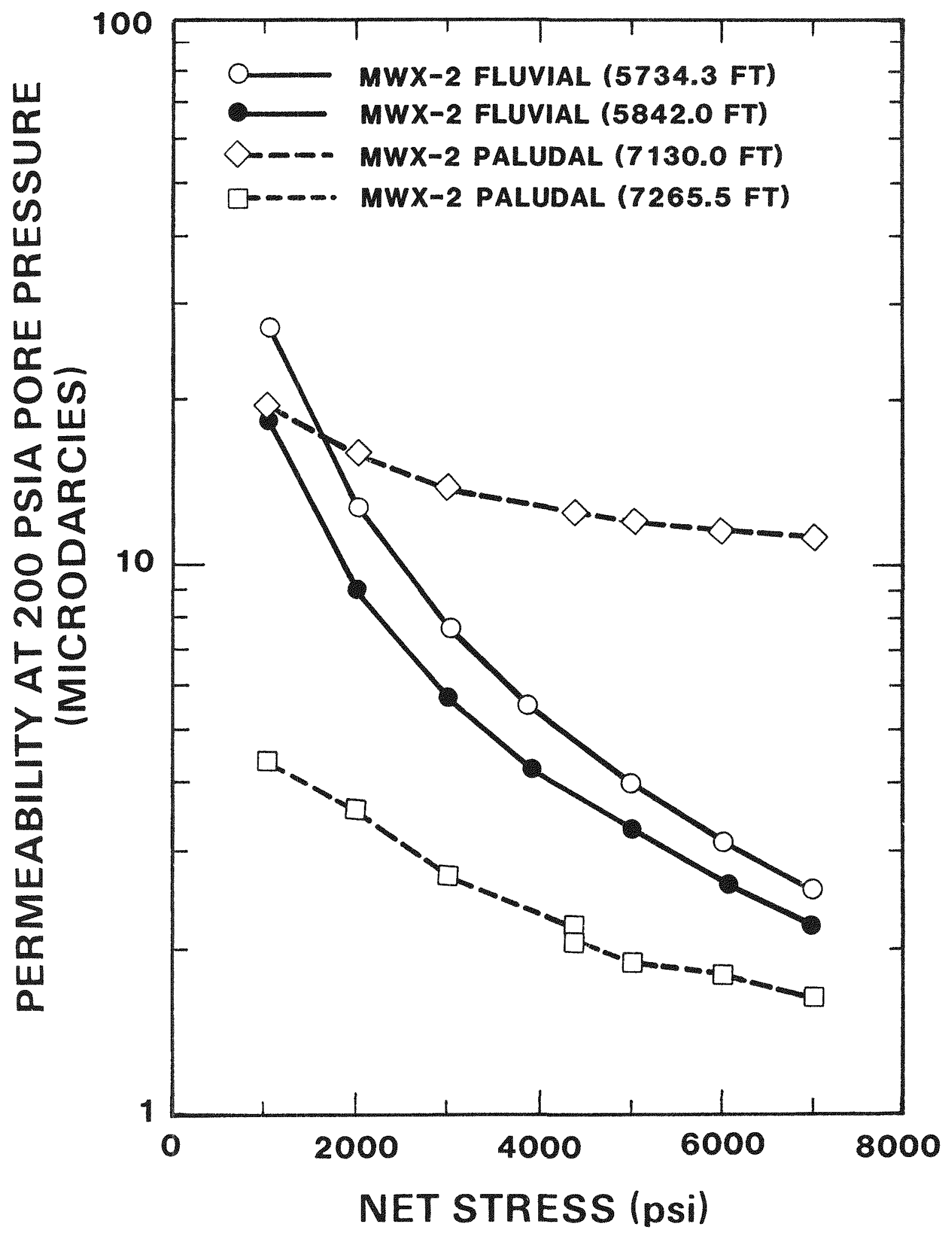

Figure 5. Permeability as a Function of Net Stress for Paludal and Fluvial Zone Samples. 
Measurements of the Effects of Water Saturation on Permeability

Effects of water saturation can reduce dry-core permeabilities an order of magnitude or more (Figure 6) (IGT Relative Permeability Reports, October, November, 1982, 1985; Core Labs. SCAL Reports, March 15, 1984, June 1986; Wei, 1986; Walls, Apri1, November 1982). For example, water saturations at 15 percent, 30 percent, 40 percent, and 50 percent reduced the permeabilities of a fluvial core sample by multipliers of $0.53,0.24$, 0.11 , and 0.02 , respectively, at a confining pressure of 3000 psi.

The relative permeabilities at realistic water saturations range from about a tenth of a microdarcy to a few microdarcies. Table IV summarizes the estimated permeabilities resulting from saturation of the core. The estimates were made by decreasing the abundant dry-permeability values by the same ratio as that of the water saturated to dry-permeability values taken from the few relative permeability measurements made in each zone.

Generally, the less permeable the core, the more dependent the permeability is on water saturation. Also, at higher saturations the permeabilities seem more dependent on confining pressures (Walls, April 1982). The very strong dependence of restored-pressure-state permeability on water saturation (Figure 6) demonstrates the need for accurate measurements of water saturation.

Permeability measurements on preserved core samples may give considerably lower values than those from oven-dried core. Brine and relative permeability measurements have been made on preserved core from the coastal and fluvial zones to determine the differences between ovendried and preserved tight sandstone core (New Mexico PRRC, 1987). There were several highlights of this work:

- The water saturations of four preserved core specimens were 81.5 percent (at $4916 \mathrm{ft}, \mathrm{MWX} 1$ ), 70.9 percent (at $4923 \mathrm{ft}$, MWX 3), 40.2 percent (at $4900 \mathrm{ft}$, MWX 3), and 22.1 percent (at 


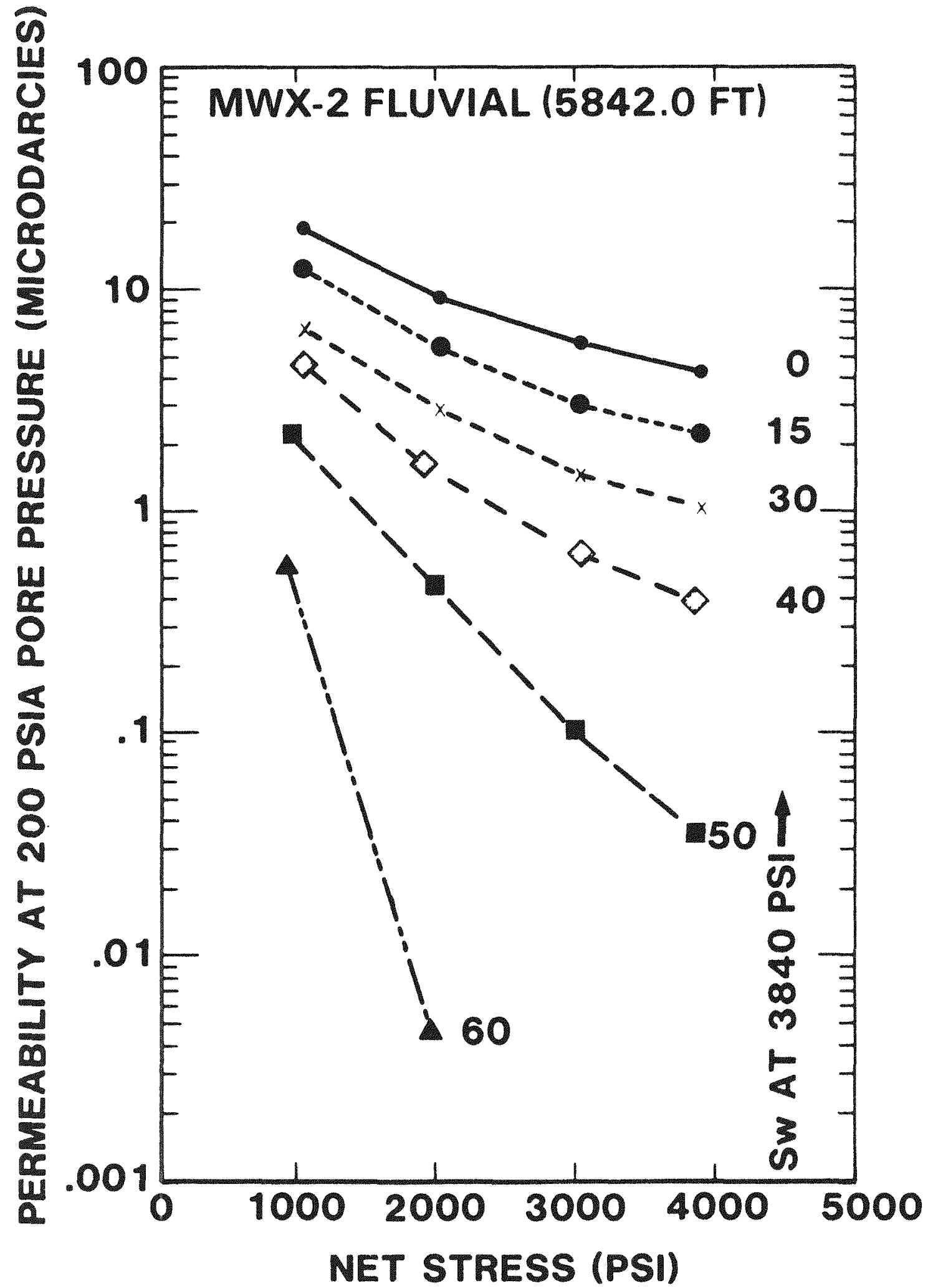

Figure 6. Permeability as a Function of Net Stress for Given Values of Water Saturation 
$5968 \mathrm{ft}$ MWX 3). Some water loss is assumed from the last sample and some water loss may be indicated from the next-to-last sample. MWX 1 and MWX 2 samples were sealed with seal peel, and the samples from MWX 3 were preserved with Core Seal from Core Laboratories. Preserved samples from the three wells had been stored for 5 yrs and, based on earlier routine analyses, they still seemed to retain their moisture.

- At low (500 psi) confining pressures the brine permeability of the preserved-core is only about one half that of the resaturated ovendried core (Figure 7).

- At confining pressures characteristic of the coastal and fluvial zones (2000 psi), the permeabilities of the preserved core are about 25 to 30 percent less than the permeability of the resaturated core. At higher confining pressures this difference lessens.

- Gas permeabilities of the preserved core were usually less than the permeability of the resaturated dried core at all water saturations. As water saturations becomes less, the differences become less (Figure 8 ).

\section{Pressure Core Measurements}

A pressure core operation was performed in the $E$ and $F$ fluvial sands, at 5485 to 5500 and 5551 to $5581 \mathrm{ft}$, during the drilling of MWX 2 (Sattler, 1984). The goals of this operation were (1) to obtain accurate water saturation data, (2) to measure the amount and composition of gas on a foot-by-foot basis, and (3) to recover fluids for water-chemistry analyses. This was felt to be a novel approach for accurate water saturation measurements in tight sandstone core.

Several changes in usual pressure coring procedures were adopted, including the development of an organic, noninvasive coring fluid to help 


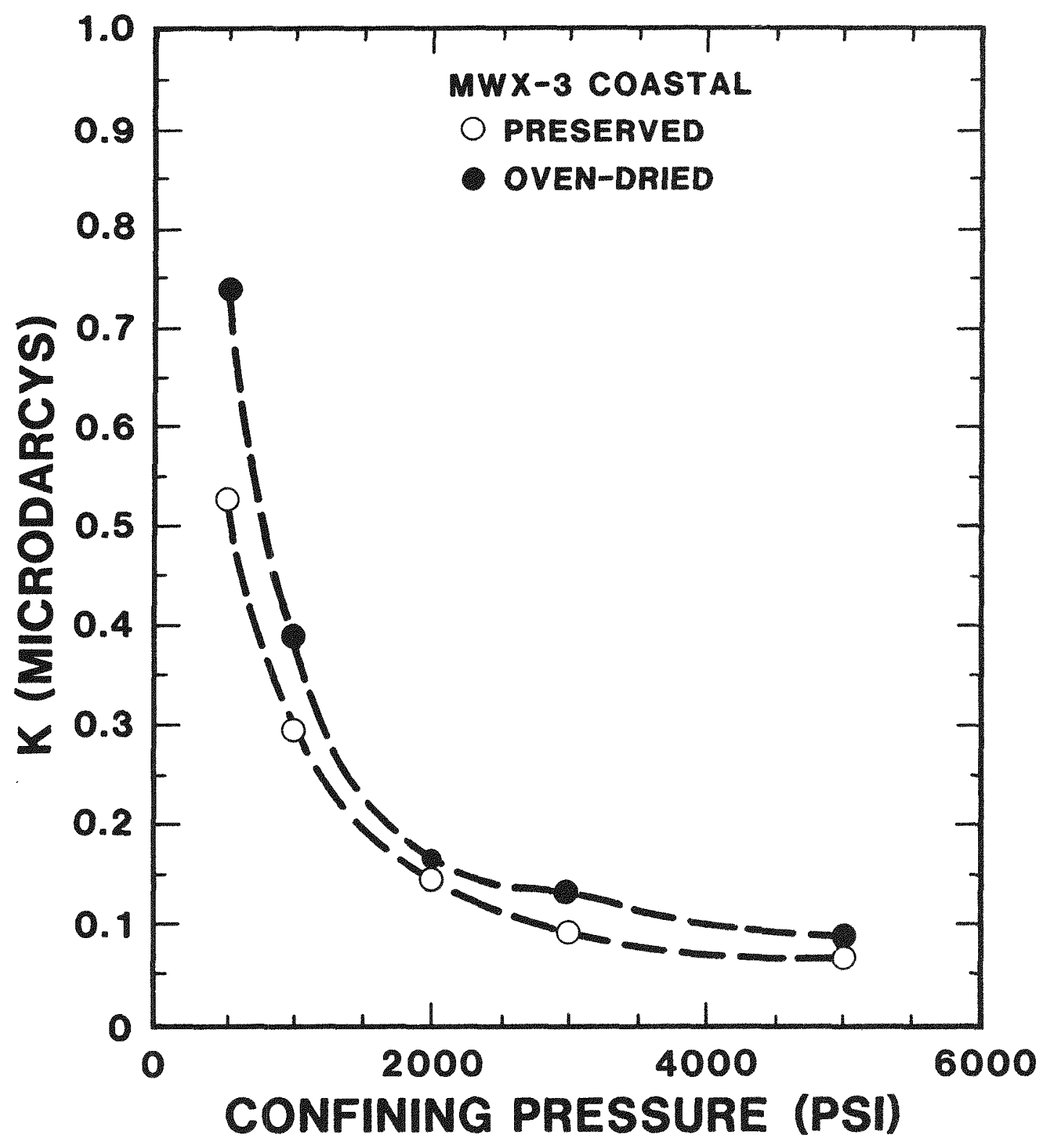

Figure 7. Comparison of Brine Permeabilities of Preserved Core and Resaturated Oven Dried Core. 


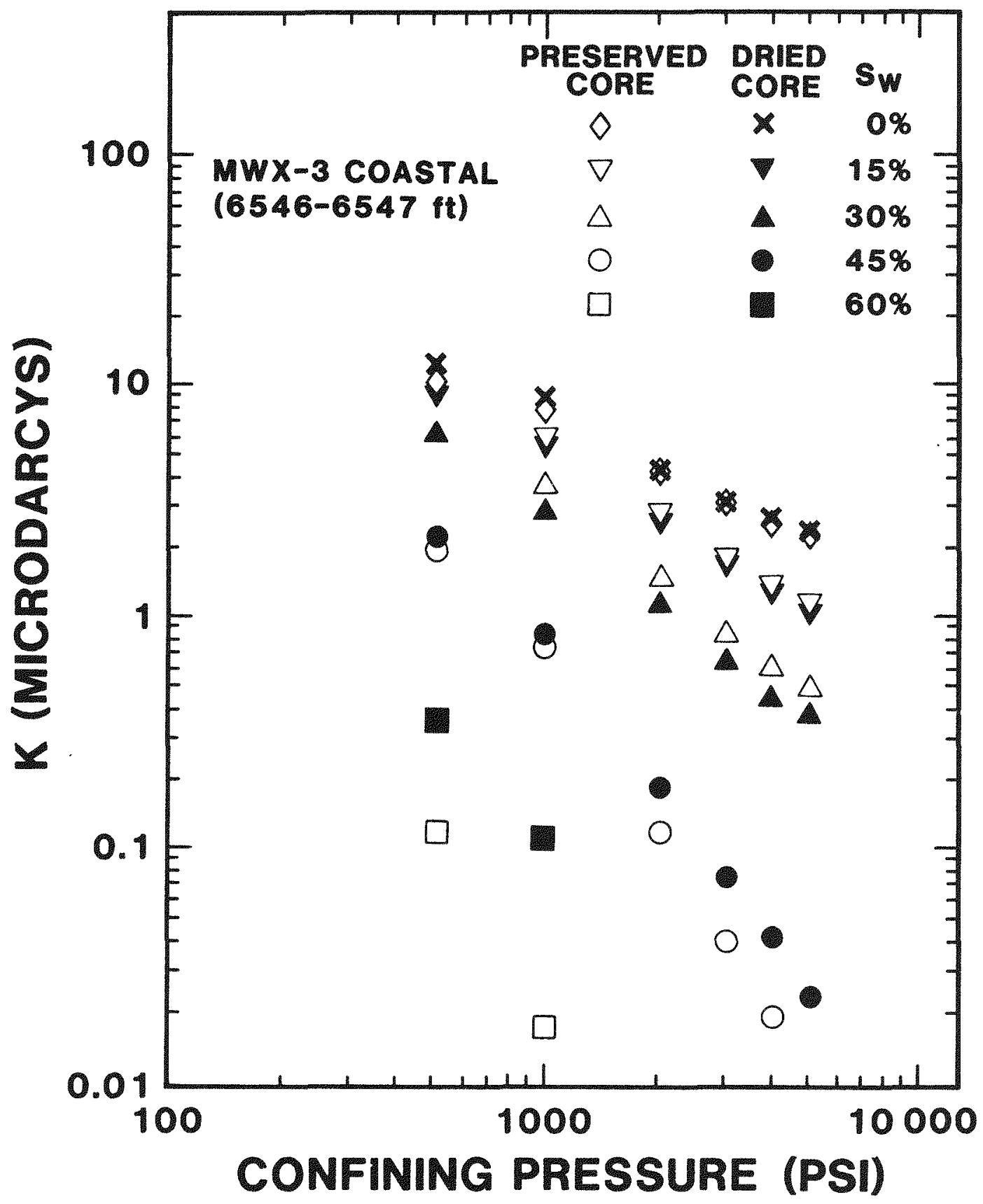

Figure 8. Comparison of Relative Gas Permeabilities of Preserved Core Resaturated and Oven Dried Core. 
preserve the water saturation. The pressure core barrel was modified so that gas, not trapped during the freezing process, would not be lost. During the operation, three 15 -ft-long pressure core barrels were taken; they were filled with reservoir rock.

Water saturation data were obtained on the pressure core first by Dean Sark distillation and later by vacuum oven-drying. The Dean Stark distillation lasted 8 days, and the vacuum oven-drying (at $240^{\circ} \mathrm{F}$ ) lasted three more weeks. Not only was there core weight loss from the Dean Stark distillation but additional weight loss occurred from the vacuum ovendrying. Analyses of the data (Sattler, 1984) suggests the added weight loss is due mainly to removal of additional connate water from tight core. The additional weight loss (Figure 9) was not considered to be due to water from invasion of core, to clay-bound water, or to water from decomposition of some of the organic matter in the rock during the vacuum oven-drying. The analysis suggests that water extraction should be carried on for a long time, and that the Dean stark procedure may not be the most efficient way to extract water from tight sandstone core.

No water was recovered during the thawing of the pressure core prior to the Dean Stark analyses, probably because permeabilities of the samples were too low. Gas was recovered during the thawing process and the gas was analyzed on a foot-by-foot basis (Sattler, 1984).

The failure of one pressure core barrel, coring from 5551 to $5566 \mathrm{ft}$, to hold pressure during retrieval of the core was a bonus, because it allowed identical analyses to be made on both pressurized and unpressurized core from the same sandstone lens. These analyses showed no water saturation differences on rock with the same porosities. Under the conditions described here pressure core and the more routine water extraction methods can give the same results if the extraction methods are carried on long enough. The newer noninvasive techniques (Wellington and Vinegar 1987, Abrams and Vinegar 1987) hold promise for unambiguous water saturation determination. 


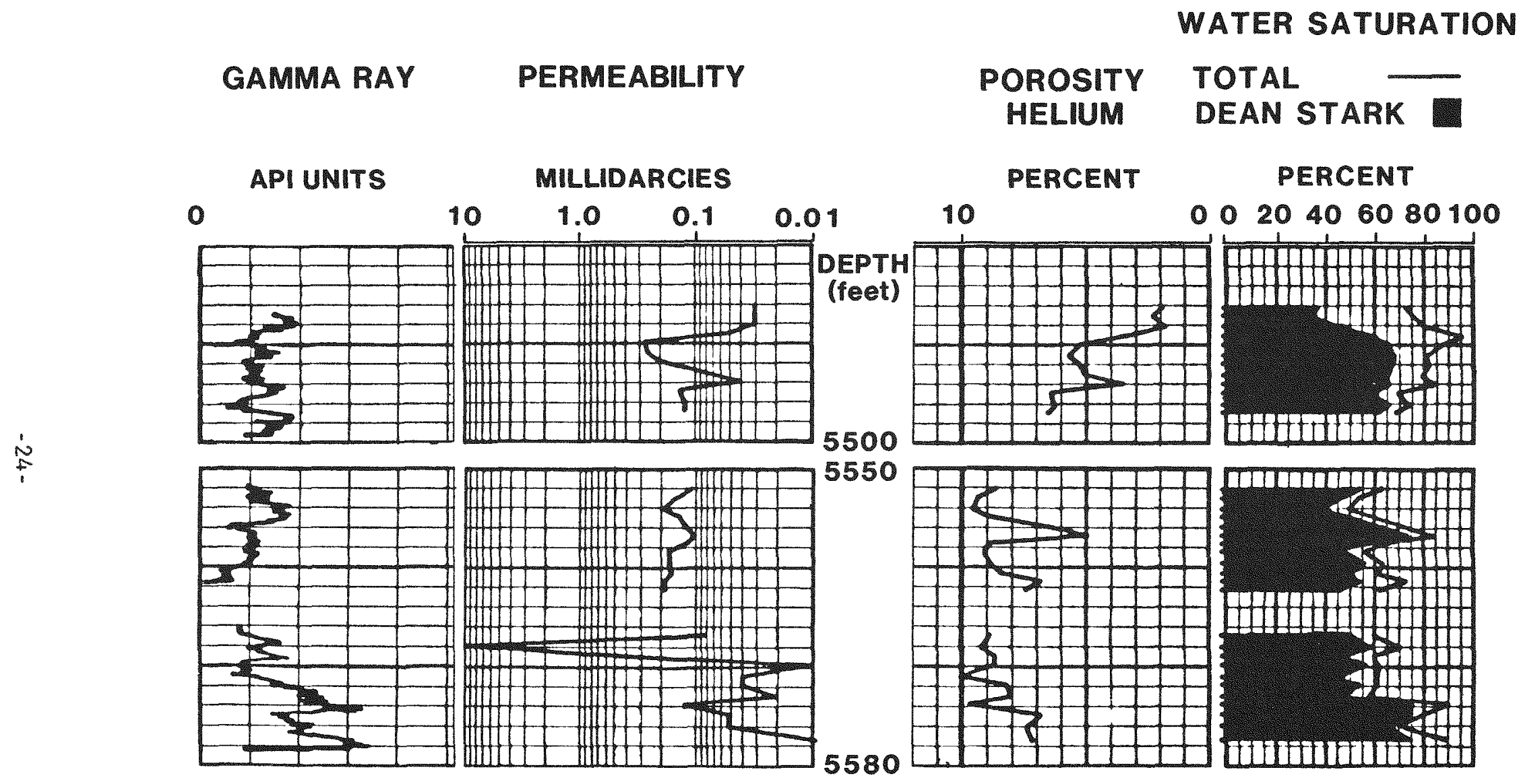

Figure 9. Presentation of Pressure Core Data 


\section{Capillary Pressure Measurements}

High capillary pressures values were obtained from MWX core samples (Core Labs., SCAL Reports, February 1983, March 15, 1984, May, June 1986; IGT Dry Core Reports, October 1982, 1984; Ward, 1987) because the rock is tight and permeabilities are low. The meaning of an "average or effective" capillary pressure in some of the lower permeability core is uncertain because the (brine) capillary pressure measurements could be performed only on the most "open" core in the zones tested. The pore capillary pressures are useful in considering invasion from drilling and formation damage during completions.

In most cases, the measured capillary pressures at realistic water saturations (Table $V$ ), range in the hundreds of psi. Thus, these sands are

Table V

Capillary Pressures to Brine at Estimated Water Saturations

$\begin{array}{lll}\text { Depth }(f t) & S_{w} & P_{c} \text { (psi) }\end{array}$

Cozzette, MWX 2

7883

7873

7138

7128

6426

6433

5829

5837
$-36$

$-36$

$-800$

$-800$

Paludal 3, MWX 2

$-27$

$>1000$

$-27$

$>1000$

Coastal yellow, MWX 1

$$
-38
$$

$-38$

$>1300$

Fluvial B, MWX 1

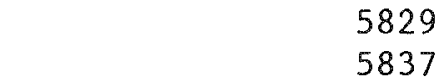

$-200$

$-900$ 
prone to invasion by drilling fluids and to inbibition from stimulation with water-based fluids. However, these pore capillary forces may actually assist in gas production from natural fractures (see section on Geologic Features Enhancing Permeability).

When mercury-injection capillary pressure curves are superimposed on the air-brine capillary pressure curves at the high-wetting-phase saturations (Figure 10), the air-brine curves are lower even with the use of the theoretical scaling factor of 5:1. At the lower saturations, the mercury-injection data suggest lower pressures. Different threshold entry pressures appear to result from the two methods. A careful examination of Purcell's data for his lower-permeability sample shows the same difference at high-wetting-phase saturations (Purce11, 1949; Walls and Amafule, 1985). The different measurements were usually performed within a couple of feet of each other.

In the region of low-wetting-phase saturations, recent work (Walls and Amafule, 1985; New Mexico PRRC, April 1988) shows fairly good agreement between the two techniques. This may have to do with a slower injection rate (Wardlow and Taylor, 1976). Even in this recent work (Walls and Amafule, 1985), the mercury curves tend to become lower as the saturation becomes low. Differences between these measurement techniques are to be expected because of complex interactions of adsorption, permeabilities, and capillary forces with brine in these narrow, clay-lined pores.

These low-permeability MWX sandstones are hydroscopic. Totally dry MWX core placed in a chamber at 90 percent humidity will attain saturation values around 25 percent (Ward and Morrow, 1987). Capillary pressures have been extended in tight sands lower water saturation values by generating desorption isotherms.

Recent attempts have been made to measure low-permeability sandstone capillary pressures at confining stress (IGT, 1987). These attempts were made in a pressurized core holder with a capillary barrier (porous plate) 


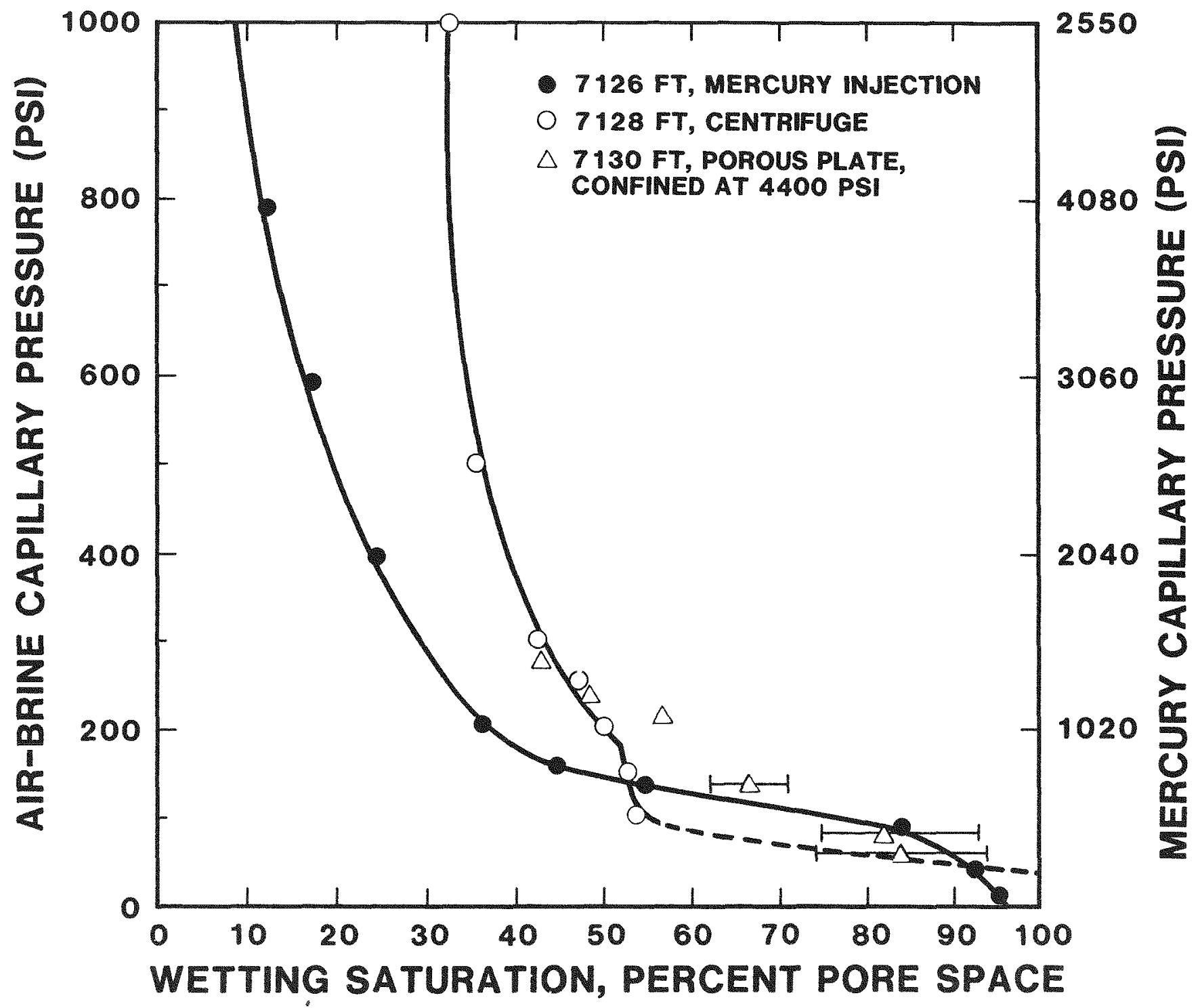

Figure 10. Air Brine, Mercury Injection, and Confined Porous Plate Capillary Pressure Data 
of formation caprock. A comparison of the data from the confined sample with that from air-brine, centrifuge method (Figure 10) shows the same, to slightly higher, capillary pressures for the confined sample at the higher brine saturations. This is expected since permeabilities decrease with increased confining pressure. Measurements involving water flow from this low-porosity, low-permeability rock are very difficult. Further, the water distributions at a given saturation in the core could differ for the two techniques and from the distribution existing in situ.

\section{Caprock Analysis}

Caprock analysis was made on samples of rock abutting the sandstone (IGT Caprock Reports, June, September 1982, 1984; Core Labs SCAL Report, March 27, 1984). The measurements included permeability to brine and the minimum gas-threshold pressure necessary to displace water. A combination of very low permeability plus a large threshold displacement pressure implies good caprock/stratigraphic barriers. Permeabilities of these materials are generally in the subnanodarcy range with threshold pressures of at least $1000 \mathrm{psi}$.

Core samples from MWX 1 were chosen at what was thought to be the boundaries of the reservoir. Core samples from MWX 2 and MWX 3 were chosen with the aid of the core gamma assembly. The samples chosen had some of the highest gamma-ray log traces seen in the abutting material and may be among the more "shaly" material between the sand lenses.

Almost all the samples tested turned out to be good caprock, at least within the limits of the test. However, the caprock testers used could only go to 1000 psi for threshold pressures, well below measured sandstone pore pressures. These measurements can therefore serve only as a qualitative indicator of caprock quality. 


\section{Electrical Measurements}

CEC measurements were made on many core samples (Table VI) (Core Labs SCAL Reports, February 1982 to June 1983, March 27, 1984, May 1984). Values range from less than $1 \mathrm{meq} / 100 \mathrm{gm}$ for marine/shoreline sands to around $5 \mathrm{meq} / 100 \mathrm{gm}$ for some coastal/fluvial zone sandstones. These values are $>10 \mathrm{meq} / 100 \mathrm{gm}$ for some of the materials abutting the sandstone lenses. When the boundaries of the sandstone lenses are reached the CEC values rise (usually markedly) because of increase in clay content. Also, when normalized, the CEC values often overlie the core gamma-ray curve for some sandstone lenses. Most CEC measurements were performed by the adsorbedwater method. Some measurements were made by using the more expensive wetchemistry method. Results from both methods were within 30 percent (Core Labs SCAL Report, June 1983).

Formation factor and resistivity index measurements were made on selected core samples Table VII (Core Labs SCAL Reports, July 1982, August 1984, May 1986, November 1987). The values of the cementation exponents $m$ and $m *$, derived from a display of formation factor vs porosity, do not seem to vary greatly with depositional environment. These cementation exponents, $m$ and $\mathrm{m}^{*}$, differ from each other by about 10 percent. The value of $\mathrm{m}$ is around 1.8 and $\mathrm{m} *$ is around 2. There is a greater variation in the values of the saturation exponents, $n(1.08$ to 1.85$)$ and $n *$ (1.47 to 2.55) which were derived from a display of resistivity index vs water saturation. These "starred" shaly sand values (Waxman and Smits, 1968, Waxman and Thomas, 1974) were obtained from the appropriate core CEC values. Water was removed from core plugs used in the determination of the resistivity indexes and associated saturation exponent by using a centrifuge. As mentioned, measurements of the removal of small amounts of water from this low-permeability core are very difficult. Also the distribution of the brine remaining in the plug may not be that distribution that characterizes in situ conditions. This may result in different measured values for the electrical characteristics. It is difficult to judge the reliability of the saturation exponent values. 
Table VI

CEC Values for MWX Sands (meq/100 g)

\begin{tabular}{|c|c|c|c|}
\hline Sand & $\begin{array}{l}\text { Average } \\
\text { Value } \\
\text { for Sand }\end{array}$ & $\begin{array}{l}\text { Typical Value } \\
\text { for Material } \\
\text { Abutting Sand }\end{array}$ & Comments \\
\hline Corcoran, MWX 2 & 1.1 & 5 & $\begin{array}{l}\text { CECs Low and Moderately Uniform } \\
\text { Through Center of Sand. }\end{array}$ \\
\hline $\begin{array}{l}\text { Cozzette, MWX 1, MWX } 2 \\
\quad \text { (Production Zone) }\end{array}$ & 0.5 & 17 & $\begin{array}{l}\text { CECs Low and Uniform Vertically } \\
\text { and Horizontally. }\end{array}$ \\
\hline (Bitumen Zone) & 1.5 & & CECs Uniform Across Zone. \\
\hline Paludal Zone 3, MWX 2 & 1.7 & 6 & $\begin{array}{l}\text { CECs Relatively Low for Lenticular } \\
\text { Sand. }\end{array}$ \\
\hline Coastal Yellow, MWX 1 & 2.7 & 12 & $\begin{array}{l}\text { CECs Among Highest of Sandstone } \\
\text { Studied and Are Not Uniform Across } \\
\text { Sand. }\end{array}$ \\
\hline Fluvial B, MWX 1 & 2.1 & 10 & $\begin{array}{l}\text { CECs Relatively High and Not } \\
\text { Uniform Across Sand. }\end{array}$ \\
\hline Fluvial E, MWX 2 & 2.2 & - & $\begin{array}{l}\text { CECs Relatively High and Not } \\
\text { Uniform Across Sand. }\end{array}$ \\
\hline Paralic & 0.9 & 12 & $\begin{array}{l}\text { CECs Lower Than Lenticular Zones } \\
\text { Comparable to Those of Marine } \\
\text { Blanket Sands. }\end{array}$ \\
\hline
\end{tabular}


Table VII

Cementation and Saturation Exponents From Formation Resistivity Factor and Resistivity Index Determinations

\begin{tabular}{lccccc}
\hline & $\begin{array}{c}\text { Effective } \\
\text { Overburden } \\
\text { Pressure, psi }\end{array}$ & $\begin{array}{c}\text { Cementation } \\
\mathrm{m}\end{array}$ & $\begin{array}{c}\text { Exponent } \\
\text { M* }\end{array}$ & $\begin{array}{c}\text { Saturation } \\
\mathrm{n}\end{array}$ & $\begin{array}{c}\text { Exponent } \\
\mathrm{n} *\end{array}$ \\
\hline MWX 2 & 0 & 1.82 & 2.03 & 1.08 & 1.47 \\
Paludal Zone & 200 & 1.92 & 2.12 & & \\
& 3600 & 1.95 & 2.17 & & \\
MWX 1 & 0 & 1.74 & 1.96 & 1.85 & 2.55 \\
Coasta1 Zone & 200 & 1.79 & 1.98 & & \\
& 3000 & 1.88 & 2.09 & & 1.83 \\
MWX 1 & 0 & 1.72 & 1.92 & 1.37 & \\
Fluvia1 Zone & 200 & 1.79 & 2.00 & & \\
& 3000 & 1.89 & 2.08 & & \\
\hline
\end{tabular}

Additional formation factors have been measured at pressures from 1000 to 5000 psi (New Mexico PRRC, 1987). Estimated cementation exponents, m, from formation factors around $3000 \mathrm{psi}$ are, very roughly, 20 percent higher than the values in Table VII. The values of $\mathrm{m}$ and $\mathrm{n}$ in Table VII are comparable with other measurements made in tight sands (Rosepiler, 1981).

Geologic Features Enhancing Permeability: Filled Natural Fractures and Carbonaceous Stringers

Natural fractures appear to dominate unstimulated production, since the formation permeabilities exceed matrix permeabilities by a least an order of magnitude in the two blanket and eight lenticular sands tested (Figure 11) (Branagan, 1984, 1985, 1987; Sandia/CER Final MWX Final Report Series I to IV). Permeability measurements were made in naturally fractured core to help explain this discrepancy.

Dry permeabilities of core plugs containing filled, narrow, natural fractures were measured and compared with permeabilities derived from 


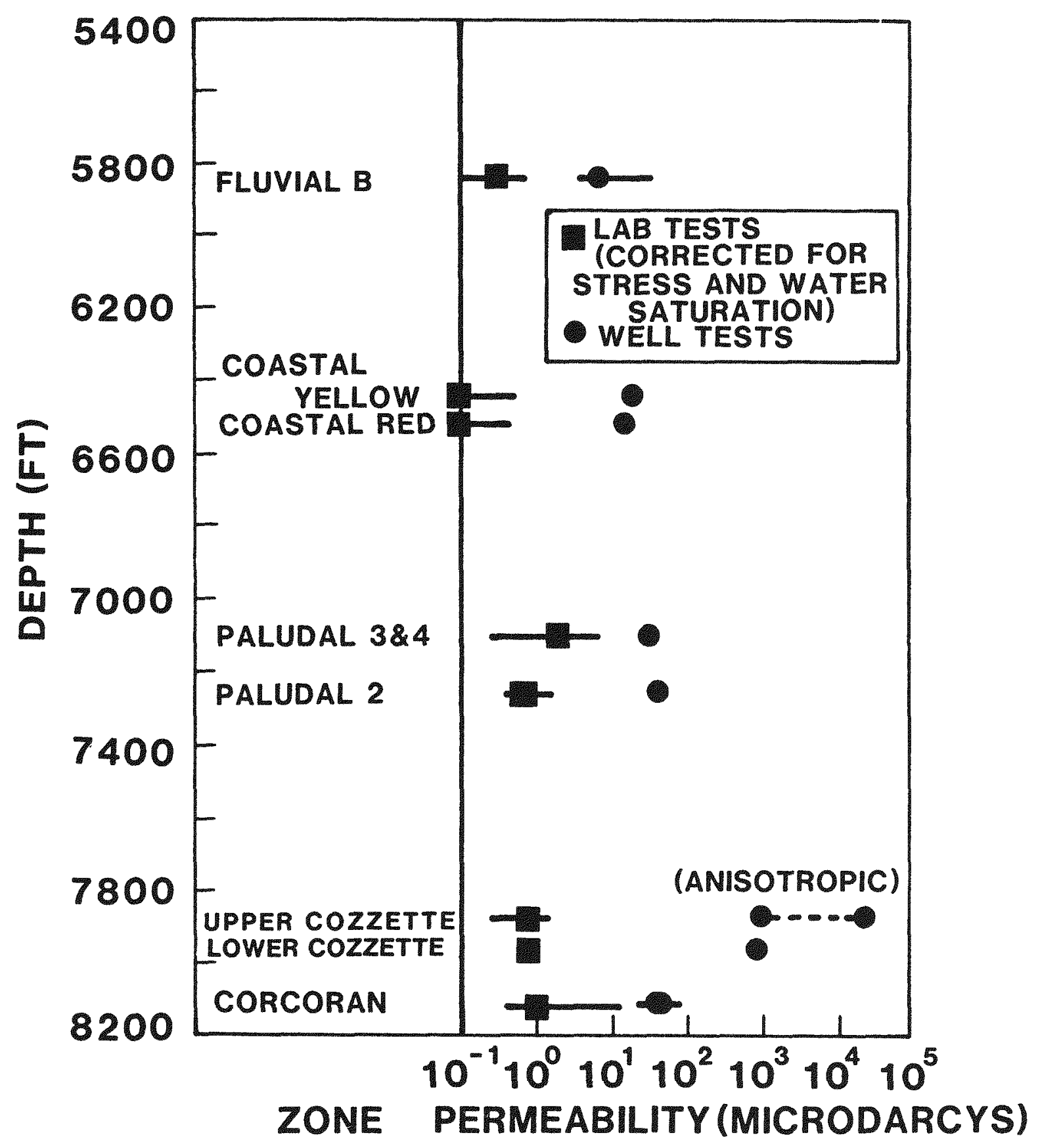

Figure 11. Formation Permeability From Production Testing vs Permeability From Core 
adjacent matrix rock (Core Labs SCAL Reports, August 1984, December 1985, and June 1986; Lorenz, 1986). On the average, the dry permeabilities of the fractured-core plugs along the fractures were significantly higher than those from the unfractured plugs, sometimes by over an order of magnitude (Figure 12) (Lorenz, 1986). Even core plugs with narrow calcite-filled fractures provide, on the average, some permeability enhancement. Measurements were also made perpendicular to the filled fractures (Core Labs SCAL Report, March 15, 1984; New Mexico Tech, 1985, 1986, 1987). There usually appears to be some permeability enhancement, although the greatest enhancement was found along the fractures. Moreover, only wellcemented core plugs survived the coring and machining process; core with more open fractures often did not.

Dry permeabilities of whole core containing natural fractures were measured and compared with permeabilities derived from adjacent matrix (Litton, April 1987). There was significant increase in the permeabilities of fractured core along the fracture direction over the permeabilities of the matrix plugs in four of the six whole core samples. Both the fractured core and associated matrix plugs had extremely low permeability in the other two cases (Figure 13).

Permeabilities of fractured whole core were measured at various water saturations and compared with matrix permeabilities from adjacent plugs at the same water saturations (Figure 14) (Litton, July 1987; New Mexico Tech, 1987). The measurements, made along the fracture direction, revealed the following:

- The permeability of the core with natural fractures is much greater than that from the matrix rock alone at zero percent water saturation.

- As expected, the permeability of the associated matrix plug is strongly dependent on water saturation, and decreases rapidly with an increase of water saturation. 


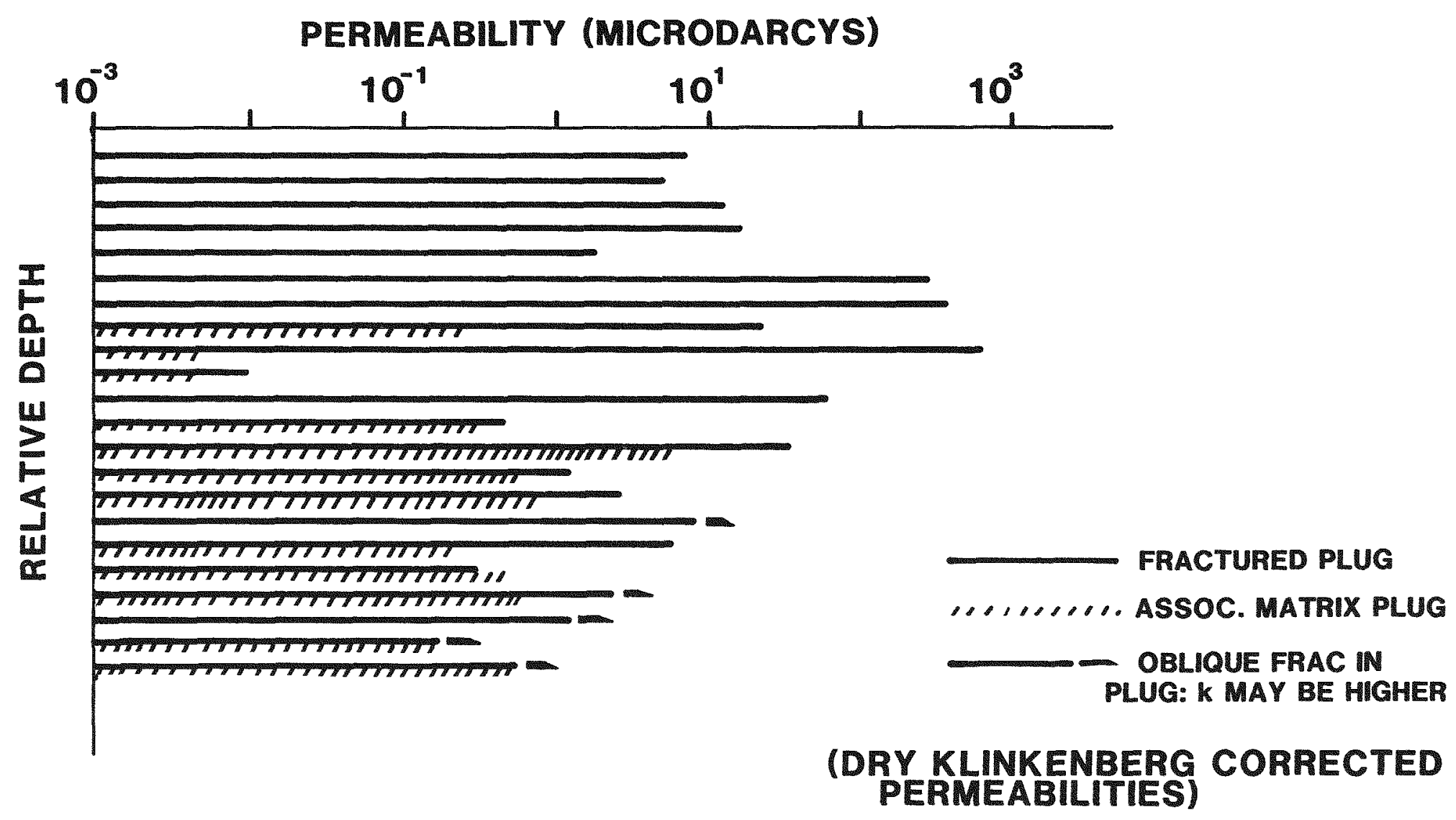

Figure 12. Permeability of Core Plugs With Natural Fractures vs Those of Associated Matrix Rock 


\section{Whole Core Permeability}

PERMEABILITY (microdarcies)

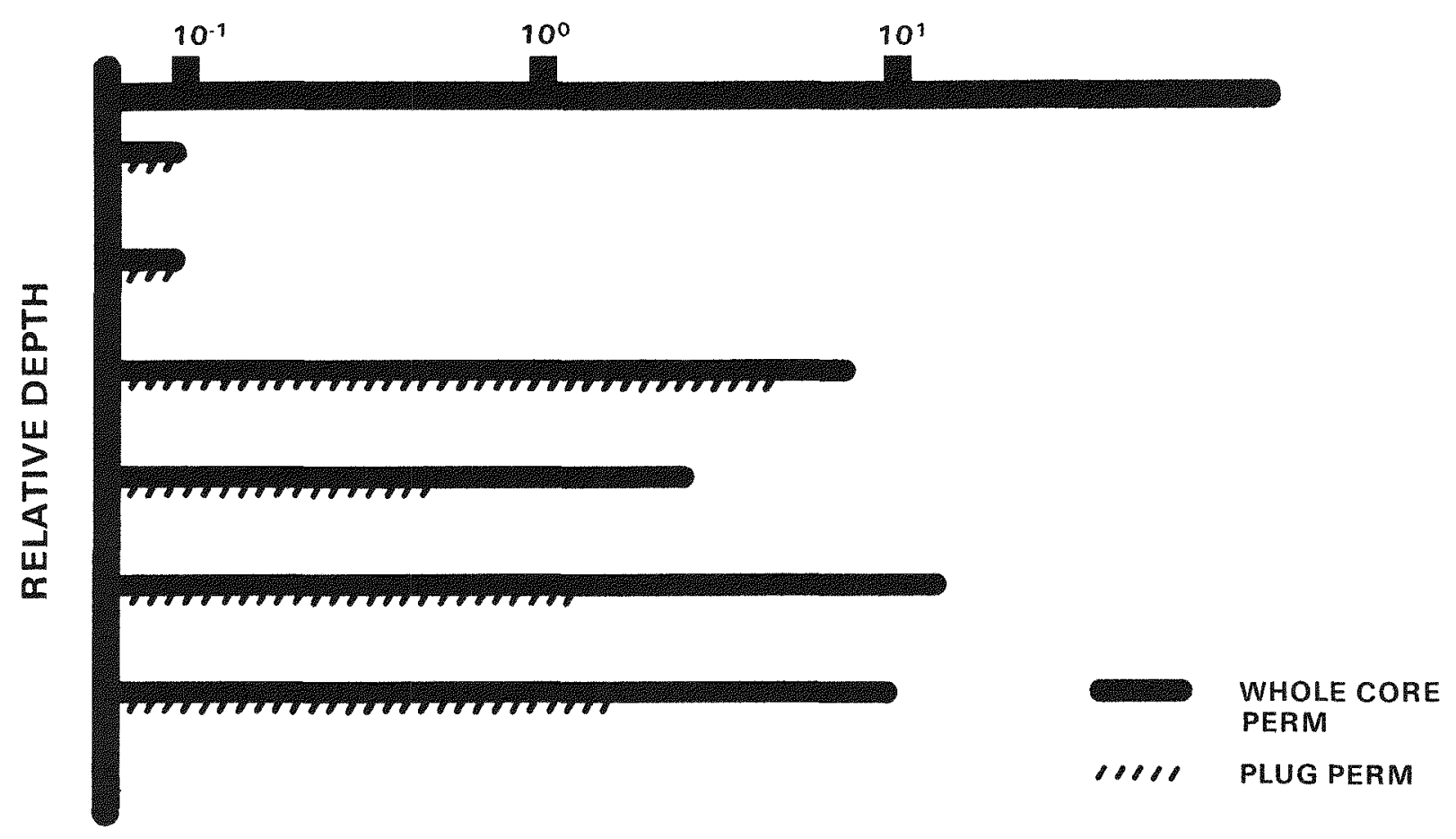

FRACTURED WHOLE CORE PERMEABILITY

VS THAT OF ASSOCIATED MATRIX PLUG

( $w /$ o fracture)

\section{- Perm enhancement seen in natural fractures from core plugs verified in whole core}

Figure 13. Fractured Whole Core Permeability vs that of Associated Matrix Plug 


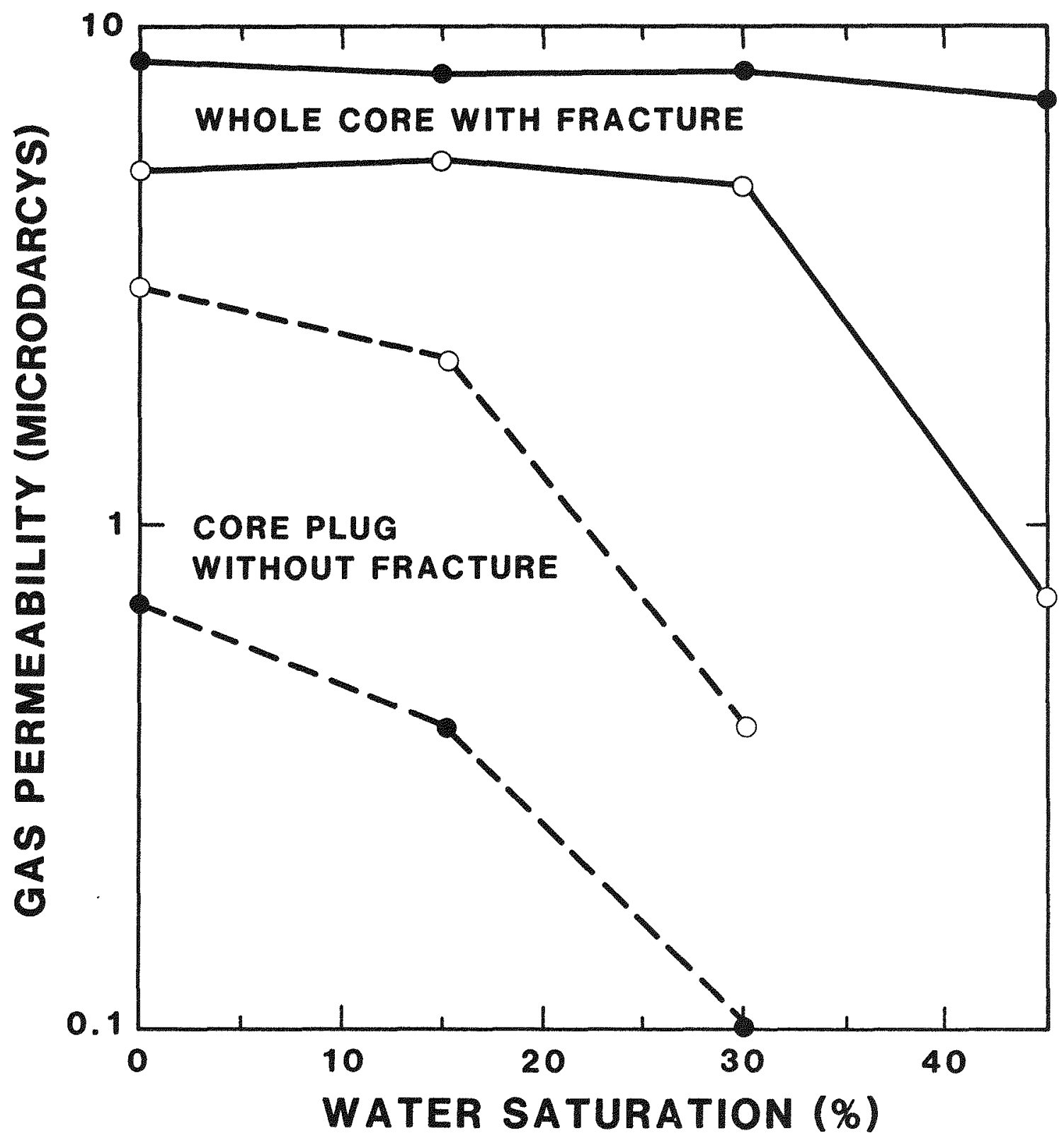

- MARINE SANDSTONE $8113 \mathrm{ft}$ CONFINING PRESSURE 6000 PSI

O COASTAL SANDSTONE $6458 \mathrm{ft}$ PORE PRESSURE 4000 pSI WHOLE CORE ( 4 inch diameter)

- - CORE PLUG (1 inch diameter)

Figure 14. Comparison of Fractured Whole Core Permeabilities vs that of the Associated Matrix Rock as a Function of Water Saturation 
- The permeability of the core with fractures has a different dependence on water saturation than that of the matrix alone. Water saturation does not decrease permeabilities in fractured core to the degree it decreases the permeabilities of the matrix rock. (The capillary pressures of the matrix rock are high, and these forces may tend to keep the narrow natural fractures free of water.)

Permeabilities of core plugs containing carbonaceous stringers were also measured to determine if these stringers provide any permeability enhancement (Core Labs. SCAL Reports May and June 1986, Apri1 1987). There is no clear-cut pattern in these results but there is some permeability enhancement from several of the stringers. These carbonaceous stringers may intersect some of the predominantly vertical fractures in the formation.

\section{MECHANICAL ROCK PROPERTIES}

\section{Tests of Mechanical Rock Properties}

Mechanical rock properties have been conducted on a large number of MWX core samples MWX (RE/SPEC, September, October, November 1983, February, July 1984, 1985.). The greatest number of these measurements were conducted in the regions where formation testing and stimulation have taken place. Measurements were made of Young's modulus, of compressive strengths, and of Poisson's ratio at confining pressures of zero, 1,450, $2,900,4,350$ and 7,260 psi. For sandstones, Young's modulus ranges from about $2.17 \times 10^{6}$ to $5.8 \times 10^{6} \mathrm{psi}$, and compressive strength ranges from $2.3 \times 10^{4}$ to $3.8 \times 10^{4} \mathrm{psi}$. For the material abutting the sandstone (siltstones, mudstones, and shales), Young's modulus ranges from $2.1 \times 10^{6}$ to $6.5 \times 10^{6} \mathrm{psi}$, and compressive strengths range from around $1.3 \times 10^{4}$ to $5.6 \times 10^{4} \mathrm{psi}$ at realistic confining pressures. Poisson's ratio varies from about 0.2 to 0.3 for sandstones, siltstones, mudstones, and shales. Tensile strength and fracture toughness measurements were also made 
(Senseny, 1984). Fracture toughness ranges from $0.6 \times 10^{3}$ to $2.1 \times 10^{3}$ $\mathrm{psi} / \mathrm{in}$ for sandstones and from $0.15 \times 10^{3}$ to $2.3 \times 10^{3} \mathrm{psi} / \mathrm{in}$ for the material abutting the sandstones. Tensile strengths range from $0.7 \times 10^{4}$ to $2.3 \times 10^{4} \mathrm{psi}$ for sandstones and from $0.4 \times 10^{4}$ to $3.1 \times 10^{4} \mathrm{psi}$ for siltstones, mudstones, and shales. The plugs for the above sample measurements were cut vertically.

There appear to be differences in some measurements between sandstones and the abutting material. For sandstones, compressive strengths and Young's modulus increase linearly with confining pressure. Young's modulus for abutting rock is generally independent of confining pressures or decreases slightly with increasing confining pressure. Poisson's ratio for both types of materials shows no trend with changes in confining pressure.

There appears to be an additional difference in the stress-strain curves for the sandstones and the abutting rock. The sandstone stressstrain curve is nonlinear at both low and high stresses and the volumetric strain curve shows that the specimen dilates substantially before reaching its failure strength. In contrast, the stress-strain curve of the abutting material trends to be linear throughout the test, and the volumetric strain curve shows that the specimen dilates only slightly, if at all, before failure (Figure 15).

There are also some differences in the fundamental behavior in the load-crack displacement curves (Figure 16) that were generated in the fracture toughness tests (RE/SPEC, February 1984; Senseny and Pfeifle, June 1984). For sandstones, the load rises with crack-opening displacement until after reaching the load that is used to calculate the toughness. However, for the abutting rock the peak load is reached early in the test, and the load that is used to calculate the toughness is found on the declining part of the curve. The initial part of the sandstone curve also tends to be more nonlinear than the initial part of the curves from the abutting rock. Finally, the curves in Figure 16 show that the slopes of the unload/reload parts of the crack load-vs-crack opening displacement 

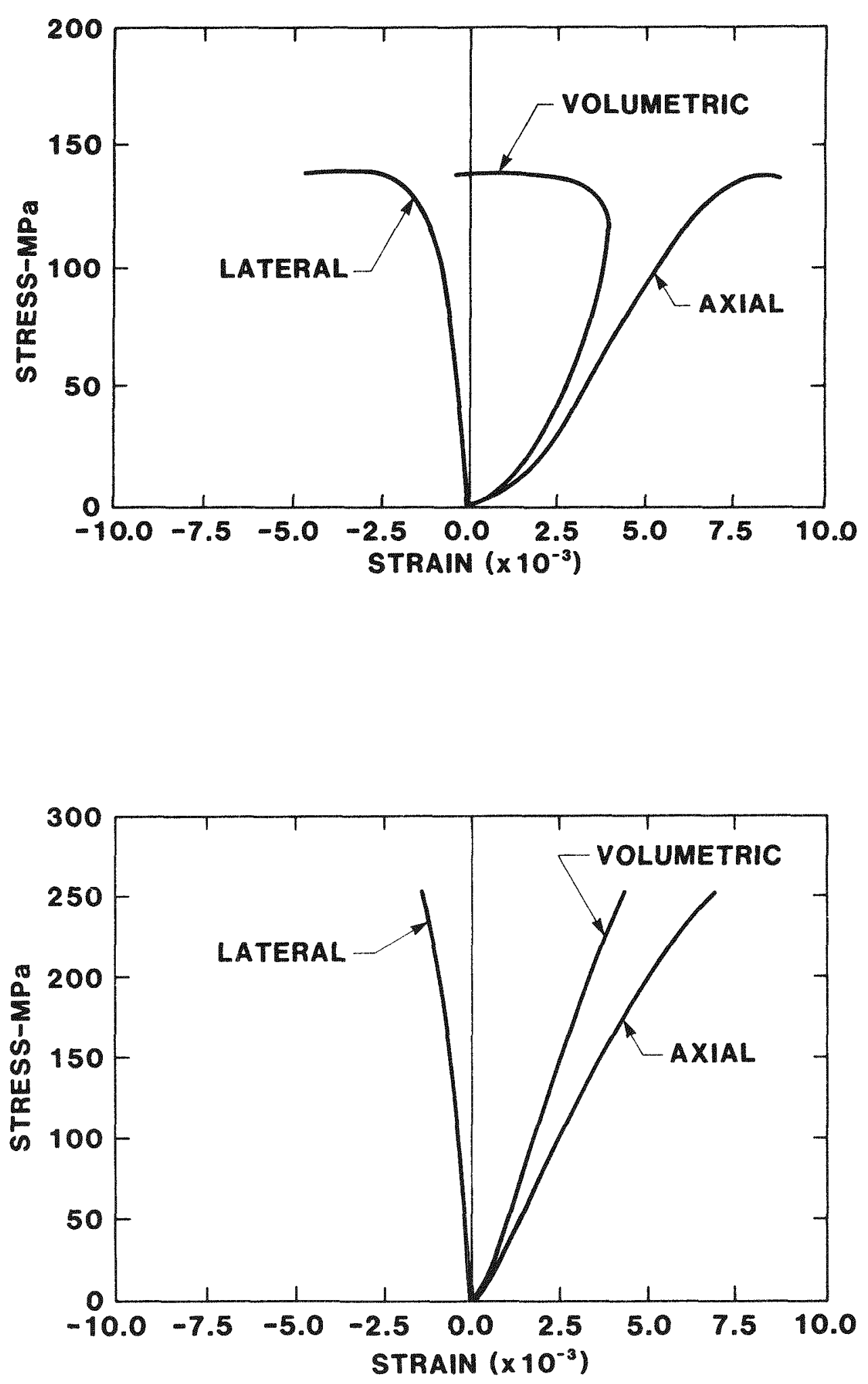

Figure 15. Stress-Strain Curves for Typical. MWX Sandstone (Top) and Mudstone/Siltstone (Bottom) 

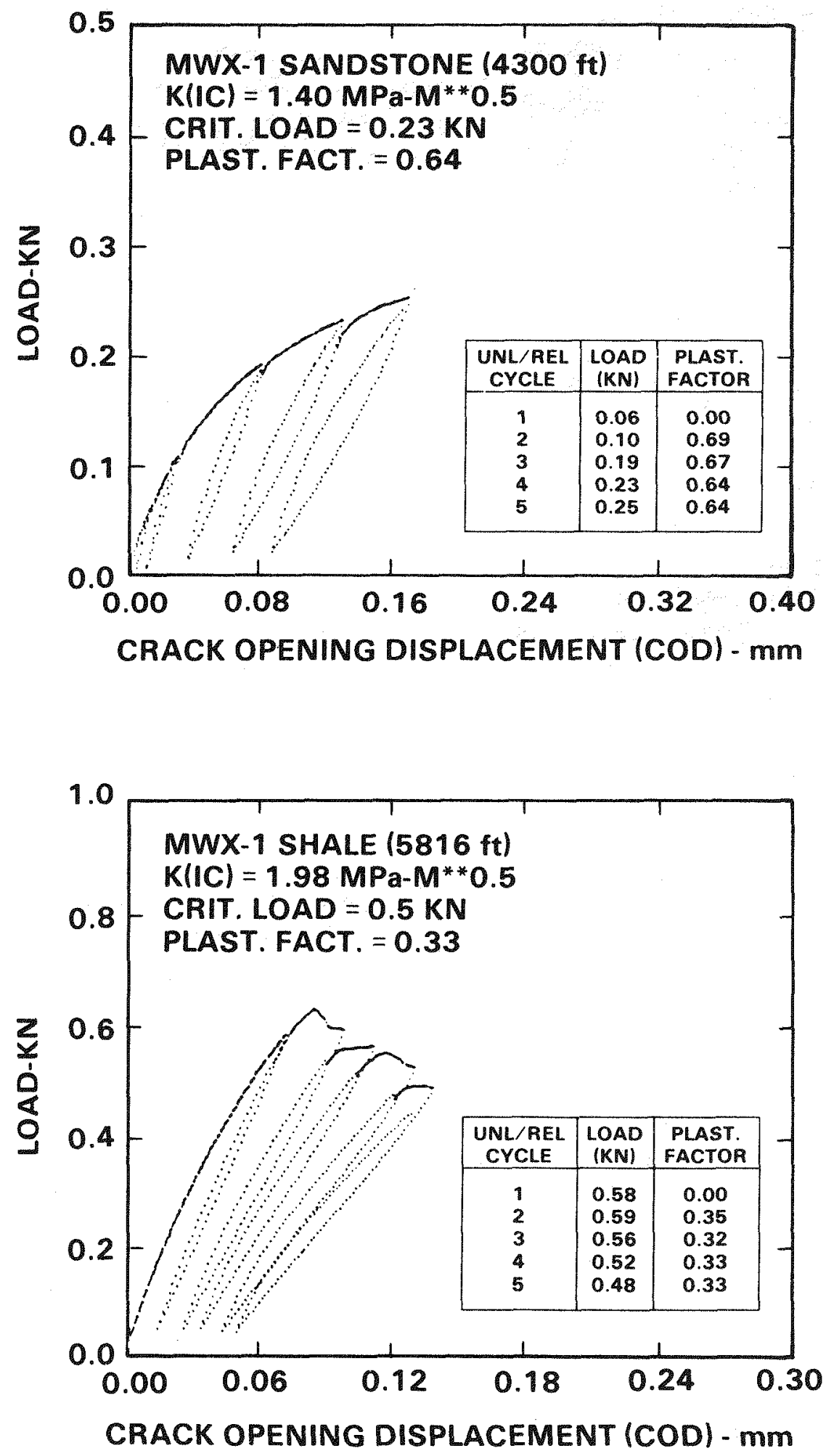

Figure 16. Crack Load-vs-Crack Opening Displacement Curves for Typical MWX Sandstone (Top) and Mudstone/Siltstone (Bottom) 
curve decrease more rapidly for these abutting rocks than for sandstone. This means that a greater plasticity correction factor must be used for the sandstone when calculating fracture toughness. The correction factor for sandstones is about 0.5 , whereas for shale it is about 0.35 .

These observations of the stress-strain curve and load-crack opening displacement curves may relate to the ease with which microcracks nucleate and grow in these materials. The nonlinearity of the sandstone stressstrain curve and the relatively large plasticity correction factor used to calculate fracture toughness of sandstone may indicate that microcracks nucleate and grow more easily in sandstones than in the materials abutting the sands. This is consistent with ASR measurements (see the section on Stress-Related Measurements of Rock Properties) which show somewhat more strain in sandstones than in the abutting materials. However, the effects of rock fabric itself in these measurements cannot be ruled out.

A limited number of comparisons were made more recently on Young's modulus values from core samples of the same depth that were cut both vertically and horizontally (Dowell Schlumberger, August 1985, October 1986). Although there were often some differences in these values of Young's modulus on a sample-by-sample basis that were probably caused by bedding structures, the differences showed no systematic trend with respect to 1ithology. These measurements and the earlier group of measurements (RE/SPEC, September, October, November 1983, February, July 1984, 1985) showed that some siltstones are among the stiffest rocks in the formation. Sandstones were next in stiffness, and most mudstones and shales were to be found among the least stiff rock (Table VIII).

Correlation of Mechanical Rock Properties with the Core Gamma and Sonic Logs

There appears to be correlation between some mechanical properties and lithology in formations of blanket morphology. For example, high moduli and compressive strength (along with low-gamma-ray and high-velocity log 
signatures) are found in the Cozzette blanket sand. The marine Mancos tongue (interfingering into the Mesaverde above the Corcoran and Cozzette sands at the MWX site) is characterized by low moduli and compressive strengths (along with high-gamma ray and low-velocity $\log$ signatures), Table VIII. The mechanical properties in these blanket sands or shales appear uniform. In the Cozzette sand this uniformity is seen both vertically and horizontally (RE/SPEC, September, October 1983).

Table VIII

Correlation of Rock Property Data in Blanket and Lenticular Regions of the Mesaverde at the MWX Site

\begin{tabular}{|c|c|c|c|c|c|}
\hline We11/Interval & $\begin{array}{l}\text { Depth } \\
(f t)\end{array}$ & $\begin{array}{c}\text { Gamma Ray } \\
\text { Number } \\
\text { (arbitrary) }\end{array}$ & 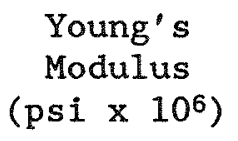 & $\begin{array}{l}\text { Compressive } \\
\text { Strength } \\
\left(\text { psi } \times 10^{4}\right)\end{array}$ & $\begin{array}{c}\text { Inverse } \\
\text { Velocity } \\
\mu \mathrm{S} / \mathrm{ft}\end{array}$ \\
\hline
\end{tabular}

Blanket and Blanket Like Sands

$\begin{array}{lllllll}\text { MWX } 2 \text { Cozzette } & 7955-7956 & 3.5 & 5.1 & 2.9 & 66 \\ \text { MWX } 2 \text { Corcoran } & 7882-7883 & 4.5 & 5.8 & 3.8 & 66 \\ \text { MWX 1 Cozzette } & 7849-7850 & 3.0 & 5.1 & 2.6 & 68 \\ \text { MWX 1 Paralic } & 4300-4301 & 3.4 & 5.4 & 2.3 & 65\end{array}$

Blanket Like Shales

MWX 2 Marine MWX 2 Marine
$8100-8101$

$7821-7822$

$$
12.5
$$

13.0

2.9

2.7
1.6

1.5

82

83

Lenticular Sands

$\begin{array}{lllllll}\text { MWX } 2 \text { Coastal } & 6520-6521 & 4.0 & 3.3 & 2.7 & 72 \\ \text { MWX 1 Coasta1 } & 6517-6518 & 5.0 & 4.1 & 2.6 & 67 \\ \text { MWX 1 Coastal } & 6451-6452 & 5.5 & 4.1 & 2.5 & 72 \\ \text { MWX } 2 \text { Coastal } & 6440-6441 & 4.0 & 4.6 & 3.1 & 69\end{array}$

Siltstones/Mudstones Abutting Lenticular Sands

$\begin{array}{llrrrr}\text { MWX } 1 \text { Coastal } & 6564-6565 & 7.5 & 5.8 & 4.5 & 63 \\ \text { MWX } 2 \text { Coastal } & 6561-6562 & 16.0 & 2.2 & 1.3 & 82 \\ \text { MWX 2 Coastal } & 6493-6494 & 11.0 & 2.5 & 1.2 & 83 \\ \text { MWX 2 Coastal } & 6462-6463 & 4.0 & 5.2 & 3.5 & 67 \\ \text { MWX 1 Coastal } & 6428-6429 & 12.0 & 2.3 & 1.5 & 84 \\ \text { MWX 1 Coastal } & 6422-6423 & 5.5 & 6.5 & 5.5 & 66 \\ \text { MWX 2 Coastal } & 6418-6419 & 4.5 & 5.2 & 3.7 & 66\end{array}$


Table VIII (Continued)

Correlation of Rock Property Data in Blanket and Lenticular Regions of the Mesaverde at the MWX Site

\begin{tabular}{|c|c|c|c|c|c|}
\hline We11/Interval & $\begin{array}{l}\text { Depth } \\
(f t)\end{array}$ & $\begin{array}{c}\text { Gamma Ray } \\
\text { Number } \\
\text { (arbitrary) }\end{array}$ & $\begin{array}{c}\text { Youngs } \\
\text { Modulus } \\
\left(\operatorname{psi} \times 10^{6}\right)\end{array}$ & $\begin{array}{l}\text { Compressive } \\
\text { Strength } \\
\left(\text { psi } \times 10^{4}\right)\end{array}$ & $\begin{array}{c}\text { Inverse } \\
\text { Velocity } \\
\mu \mathrm{S} / \mathrm{ft}\end{array}$ \\
\hline \multicolumn{6}{|c|}{$\begin{array}{l}\text { (Examples where expected correlation } \\
\text { tween sonic and gamma ray logs is poor) }\end{array}$} \\
\hline MWX 1 Fluvial & $4922-4923$ & 2.5 & 3.8 & 2.6 & 72 \\
\hline \multicolumn{6}{|c|}{ Shale Abutting Lenticular Sand } \\
\hline MWX 1 Fluvial & $4946-4947$ & 20.0 & 3.6 & 2.3 & 82 \\
\hline \multicolumn{6}{|c|}{ Non-Blanket Siltstones/Mudstones } \\
\hline MWX 1 Cozzette & $7936-7937$ & 10.0 & 4.2 & 2.0 & 68 \\
\hline MWX 2 Cozzette & $7900-7901$ & 10.0 & 5.1 & 2.2 & 68 \\
\hline MWX 1 Cozzette & $7900-7901$ & 10.5 & 4.6 & 1.6 & 68 \\
\hline \multicolumn{6}{|c|}{ Non-Blanket Carbonaceous Mudstones } \\
\hline MWX 2 Corcoran & $8140-8141$ & 10.0 & 4.3 & 1.9 & 67 \\
\hline MWX 2 Paludal & $7308-7309$ & 12.0 & 4.0 & 2.3 & 68 \\
\hline MWX 2 Paludal & $7171-7172$ & 13.0 & 3.9 & 2.2 & 75 \\
\hline
\end{tabular}

Some of the coastal lenticular sands behave like the blanket sands, at least with respect to correlation of these rock properties with the gammaray and sonic logs. These sands seem somewhat more shaly, which is consistent with the CEC data. However, the heterogeneous material abutting these sands can behave quite differently from the blanket-like shales below. These materials are mostly siltstones and mudstones with an occasional small sand "stringer." Some of the mudstones also appear to behave like the blanket shales, but some of the siltstones appear to be very stiff, quite unlike the other fine-grained rock. For example, in MWX 1 at 6422 and $6428 \mathrm{ft}$, the rock appears to have similar fine-grained 
1ithology. However, rock property data indicate very stiff rock and compliant rocks, respectively, only $7 \mathrm{ft}$ apart. Both the gamma-ray and sonic logs corroborate this: compliant rock--high gamma-ray and lowvelocity signature; stiff rock--low gamma-ray and relatively high-velocity signature (Table VIII). In these lenticular formations, properties vary rapidly over very short distances.

Usually, the gamma-ray $\log$ and the sonic $\log$ will give the same interpretation of the material type. However, there are instances in these heterogeneous Mesaverde strata that include the lenticular sandstones where the gamma-ray and sonic logs suggest different rock properties. The gammaray $\log$ suggests soft shales; the sonic $\log$ suggests stiffer sands or siltstones. Some of the high fluvial, paludal, and nonblanket layers below the upper Cozzette sand are examples (Table VIII).

It was thought that a large number of measurements would be needed to characterize core from lenticular formations. However, the use of a core gamma assembly provided an additional tool for sample selection. It usually gave a good indication of whether the material was a "clean" or "dirty" sand, or a stiff or compliant siltstone or mudstone, before the sample.was sent for analysis. The sonic $l o g$ should also be a very useful tool for sample selection of core in formations such as these.

\section{Stress-Related Measurements of Rock Properties}

Data for hydraulic fracture design has been obtained from core by means of (1) ASR measurements (Warpinski and Teufe1, May 1987); (2) DSCA (Strickland and Ren, 1980, Ren and Rogiers, 1983); and (3) a relatively new form of measurement called differential waveform analysis (DWVA) (Ren and Hudson, 1985). Its use on MWX demonstrated the capabilities of ASR for predicting hydraulic fracture azimuth from these core measurements (Teufel, September 1984; Hart, 1987; Thorne and Morris, 1987). Many improvements to ASR were developed during its extensive use on MWX (Teufe1, 1983; Warpinski and Teufel, 1987). The capabilities of DSCA and DWVA for predicting 
hydraulic fracture azimuth were also shown on MWX (Dowell Schlumberger, August 1985, October 1986), because the predicted fracture azimuth from core and that measured by borehole geophones were fairly consistent (Thorne and Morris, 1987).

ASR measurements on MWX sandstones show horizontal strain anisotropy (Teufe1, 1983, Warpinski and Teufel, May 1987). Analyses of ASR data to date on MWX core do not indicate if this degree of horizontal anisotropy is greater over particular regions of the Mesaverde, although such analyses are presently under way. The most recent MWX ASR measurements, those made on some MWX 3 nonmarine MWX mudstones, show horizontal strain isotropy, with the vertical strains being just slightly larger. The stresses are nearly isotropic. The same data show that strains in sands usually appear to be somewhat larger than in mudstones. In the nonmarine zones the vertical strain appears to be the largest; whereas in the marine blanket sands a horizontal rather than vertical stress component appears to be the largest.

Models under development (Blanton, 1983, Warpinski and Teufel, May 1987) allow the determination of stress magnitudes from the ASR results. These models supplement earlier models of the DSCA measurements (Strickland and Ren, 1980, Ren and Rogiers, 1983). It appears that the stress estimates modeled from ASR and DSCA data give fair agreement with the measured minimum principal stress data from in situ stress measurements. There are little measured data on the maximum principal stress. It is not known how effective these models are for actual hydraulic fracture design and containment considerations, especially in lenticular formations.

Permeability measurements were made on oriented paludal, coastal, and fluvial core at $N 80^{\circ} \mathrm{W}$ and $N 10^{\circ} \mathrm{E}$ (IGT, September 1984). These directions are close to the maximum and minimum horizontal stresses, respectively, at the site for these zones (Table IX) (Teufe1, 1983; Hart, 1987; Thorne and Morris, 1987; Warpinski and Teufel, May 1987). The following observations are made from Table IX. 
Table IX

Directional Permeability, MWX-3*

\begin{tabular}{|c|c|c|c|c|}
\hline \multirow[b]{2}{*}{ Depth ( $f t)$} & \multicolumn{4}{|c|}{$\begin{array}{c}\text { Dry Permeability } \\
\text { to Gas }(\mathrm{K} \infty)\end{array}$} \\
\hline & $\begin{array}{l}\mathrm{N} 80^{\circ} \mathrm{W} \\
(\mu \mathrm{d})\end{array}$ & $\begin{array}{l}\mathrm{N} 10^{\circ} \mathrm{E} \\
(\mu \mathrm{d})\end{array}$ & $\begin{array}{l}\text { \& Greater Than } \\
\text { N } 80^{\circ} \mathrm{W} \text { Perms }\end{array}$ & $\begin{array}{l}\text { Vertical } \\
\quad(\mu \mathrm{d})\end{array}$ \\
\hline \multicolumn{5}{|c|}{ Paludal } \\
\hline 7131 & 9.2 & 11.3 & 23 & 7.0 \\
\hline 7090 & 1.40 & 1.95 & 39 & 0.56 \\
\hline \multicolumn{5}{|c|}{ Coastal } \\
\hline 6514 & 0.89 & 1.20 & 35 & 0.74 \\
\hline 6446 & 1.77 & 1.88 & 6 & 1.16 \\
\hline \multicolumn{5}{|c|}{ Fluvial } \\
\hline 5830 & 2.51 & 3.75 & 49 & 4.93 \\
\hline 5737 & 1.22 & 2.16 & 77 & 1.88 \\
\hline
\end{tabular}

*Permeabilities were measured at the following values of net confining stress: Fluvial cores, 3800 psi; coastal cores, 4000 psi; Paludal cores, 4200 psi.

- In all cases, the permeabilities orthogonal to the maximum principal horizontal stresses $\left(\mathrm{N} 10^{\circ} \mathrm{E}\right)$ are greater than those along the maximum stress direction $\left(\mathrm{N} 80^{\circ} \mathrm{W}\right)$. These laboratory permeabilities may be influenced by microcracks from stress relief which in turn are influenced by the in situ stress. The amount of microcracking might be greatest along the minimum rather than along the maximum horizontal stress, and thus, the permeability might be influenced by the residual microcracks. 
- If indeed the permeabilities, as measured, are influenced by microcracking, then we might expect the vertical permeabilities to be the smallest because the vertical stresses are the predominant ones in these zones. The permeabilities are indeed the smallest for the paludal and coastal sandstone samples, but not for the fluvial samples. Effects of bedding on permeability may be important in the vertical direction. Unfortunately it is not known for sure whether or how much the microcracking is caused by stress relief from the coring process. This could add some systematic uncertainty of some tens of percent in estimating the true in situ permeability.

- The differences in the horizontal permeabilities are greatest for the fluvial zone, suggesting that the degree of horizontal anisotropy may be greater there.

\section{Importance of Net Stress in Permeability Measurements}

The permeability of one coastal and fluvial zone core plug was measured as a function of constant net overburden stress (2900 psi). This stress is simulated by constant laboratory confining pressure minus laboratory pore pressure for various pore pressure/confining pressure combinations (Walls, September 1982; Litton, July 1986, April 1987). At the time these measurements were made, the net overburden stress in the coastal/fluvial region was estimated to be around 2900 psi. The estimates of net confining stresses were made from (1) the measured pore pressure, (2) the measured minimum horizontal stress from in situ stress tests (Warpinski, 1988), (3) the maximum horizontal stress, which was estimated as about 800 psi higher than the minimum horizontal stress from open-hole stress measurement (Teufe1, June 1984) and the modeling of ASR data, and (4) an estimate of 1 psi/ft for vertical stresses. Five pore pressures were chosen with the initial pore pressure 4300 psi chosen to be close to those existing in the coastal zone. The results are given in Figure 17 . For both samples it 


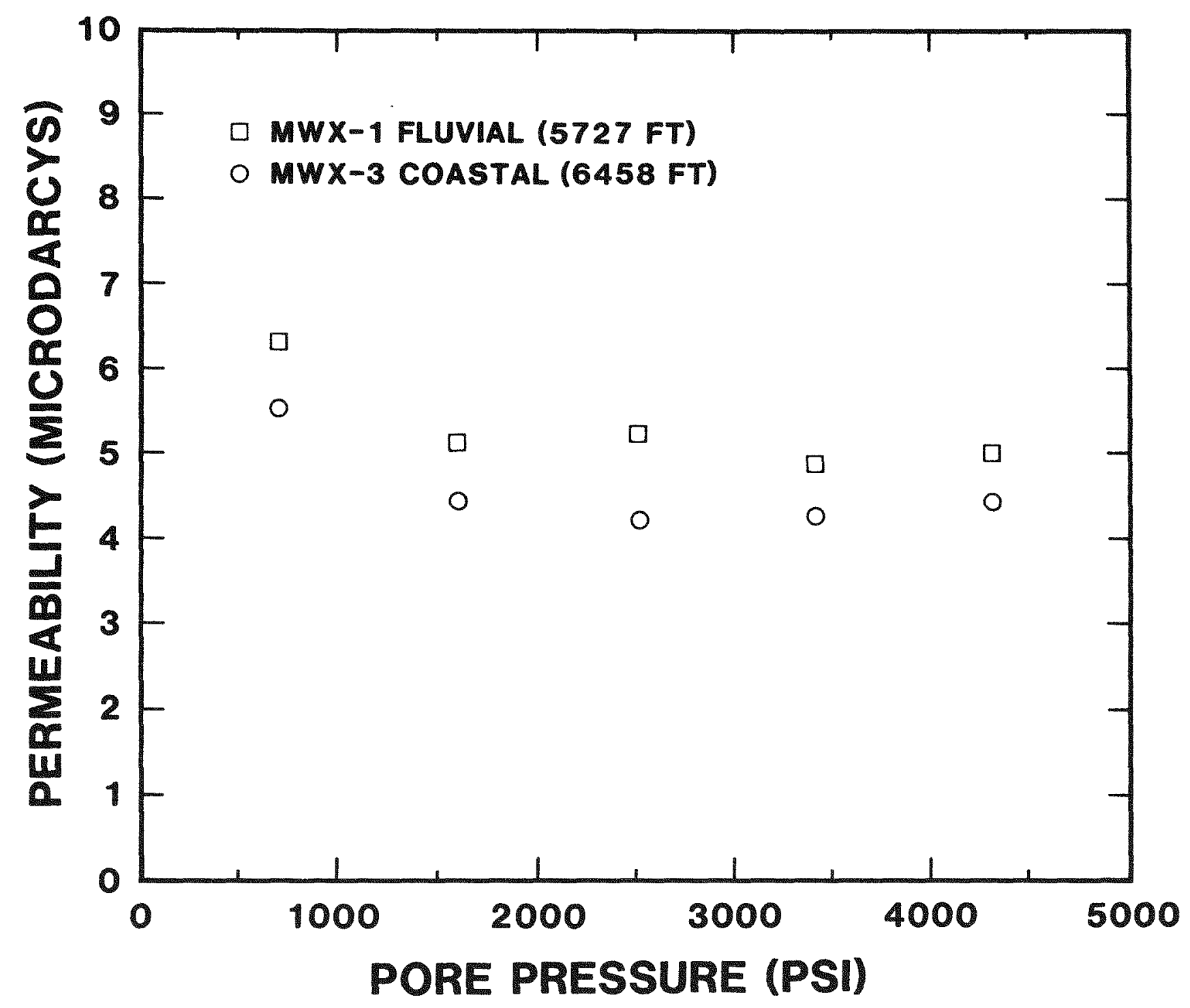

Figure 17. Permeability at Constant Net Confining Stress vs Pore Pressure 
appears that gas permeability is constant at a pore pressure of 1500 psi and above. Presumably, the increase in gas permeability at low pore pressures is due to reduction in Klinkenberg slippage effects. This figure suggests that permeability in these tight sands depends more on the value of the net stress rather than on the individual values of pore or confining pressure. It further verifies some earlier work suggesting this (Walls, April, November 1982).

\section{SUMMARY AND CONCLUSIONS}

A comprehensive analysis of the $4100 \mathrm{ft}$ of core from the lowpermeability sandstone reservoir at the DOE's Multiwell Experiment site is virtually complete. This paper contains references to over 100 documents with most pertaining to some aspect of MWX core analyses.

Reservoir parameters have been determined for the five Mesaverde depositional environments at the site. Porosities are in the range of 5 to 10 percent. Measured water saturations range from 30 to 65 percent. Matrix rock permeabilities at realistic water saturations are no greater than a few microdarcies, often less. Capillary pressures are in the range of hundreds of psi at realistic water saturations.

The average porosity in the paludal zone is somewhat higher than that of the sands in the other zones discussed. The porosities of those sandstones in other depositional environments are within one or two percent of each other. Measured water saturations are lowest in the paludal zone, the Cozzette and coastal zone have somewhat higher saturation values with the Corcoran and fluvial sands having even higher values. Above the coastal zone, the water saturation increases with decreasing depth and the paralic sand has the highest average water saturation value of the sands examined here. The permeability of the paralic sand is relatively high. In the sands tested, permeabilities are generally higher in the paludal zone and lowest in the fluvial zone. The maxine blanket sands and the coastal sands have about the same permeabilities. 
It appears as if the matrix rock would be susceptible to inhibition from water-based drilling fluids or water-based fracture fluids. Based on both core and production data, it appears that natural fractures dominate production but at reservoir conditions, the natural fractures may be expected to be fairly dry.

Additional conclusions are:

- Differences in the petrophysical properties between the blanket and lenticular sandstones are often distinct and more pronounced than differences between the petrophysical properties of the different lenticular depositional environments.

- Fair-to-limited success was achieved in correlating some aspects of reservoir parameters with mineralogy-petrology data.

- Accurate water saturation data were determined for tight sandstone under a limited set of conditions.

- Brine and mercury capillary pressures are similar in spite of the complexities of the interactions between the narrow pores and the brine.

- The brine and relative permeabilities of preserved core are less than those of resaturated core. At realistic confining pressures this decrease is in range of 25 to 30 percent for brine permeabilities.

- The permeabilities of a pair of tight sandstone core plugs appear to depend more on the net stress (confining stress minus pore pressures) than on the individual values of either the confining pressures or the pore pressures. 
- The behavior of moduli and of fracture toughness for sands and for siltstones/mudstones/shales are distinctly different.

- ASR/DSCA data appear to be adequate at least for fracture azimuth (stress orientation) predictions. It was not possible to assess the value of modeling ASR/DSCA data for hydraulic fracture design. 


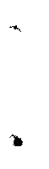




\section{REFERENCES}

Abrams, A. and Vinegar, H. J., "Impaired Mechanisms in Vicksburg Tight Gas Sands," SPE 13883, Proceedings of the SPE/DOE Low Permeability Gas Reservoirs, Denver, May, 1987.

Bendix Field Engineering (Grand Junction) Reports on Mineralogic and Petrographic Analyses of All of the Major Intervals of the Mesaverde at MWX, July 2, 1982, July 20, 1982, August, October, December 1982, March, April, May, July, August, September, October, December 1982, January, March 11, March 29, May, July, August, September, November, December 1983, January, February, May, July, August 1984.

Blanton, T. L., "The Relation Between Recovery Deformation and In Situ Stress Magnitudes," SPE 11624, Proceedings of the 1983 SPE/DOE Symposium on Low Permeability Gas Reservoirs, Denver, Colorado, March 1983.

Branagan, P. T., "Interference Testing of the Naturally Fractured Cozzette Sandstone: A Case Study at the DOE MWX Site," SPE/DOE/GRI 12869, Proceedings of the Unconventional Gas Symposium, Pittsburgh, Pennsylvania, May 1984.

Branagan, P. T. et al., "Comprehensive Well Testing and Modeling of Pre and Post Well Performance of the MWX Lenticular Tight Gas Sands," SPE/DOE 16387 Proceedings of the 1985 SPE/DOE/Joint Symposium on Low Permeability Reservoirs, Denver, Colorado, May 1985.

Branagan, P. T. et al., "Case History of Hydraulic Fracture Performance in the Naturally Fractured Paludal Zone: The Transitory Effects of Damage," SPE/DOE 16398, Proceedings of the 1987 SPE/DOE Joint Symposium on Low Permeability Reservoirs," Denver, Colorado, May 1987.

Core Laboratories Routine Analyses Reports, RP-2-6714 November 1981, RP-26806 March 1982, 3806-7119 July 1983.

Core Laboratories Special Core Analysis (SCAL) Reports, 203-820007 February 1982, 203-820022 March 1982, $203-82023$ July 1982, 203-820044 September 3, 1982, 203-820027 September 14, 1982, 203-820088 January 1983 (CEC only), 203-820108 February 1983, 203-820075 February 1983, 203-82104 June 20, 1983, 203-830019 June 24, 1983, 203-830070 November 1983, 203830024 March 15, 1984, 203-840055 March 27, 1984, 203-840016 May 1984, 203-840026 August 1984, 203-840077 November 1984, 203-850062 December 1985, 203-860019 May 1986, 203-860024 June 1986, 203-86053 September 1986, 203-87005 April 1987, 203-87050 November 1987.

Core Laboratories Report, P83012, January 1984.

Dowe11 Research Laboratory (Tulsa) Report, "Differential Strain Curve Analysis on MWX 1 Cores," August 1982. 
Dowel1 Schlumberger Formation Analysis Laboratory (Tulsa) Reports, "Multiwell Experiment Core Analyses of the MWX 1, MWX 2, and MWX 3 Wel1s," Interim Report, August 1985; "Multiwe11 Core and Fluid Analyses of MWX 1, MWX 2, and MWX 3 (we11s), " supplemental report, February 1986; "Formation Evaluation of MWX-1, MWX-2 and MWX 3 (Fluvial Interval)," October 1986.

Finley, S. J., internal Sandia memos describing the fractures of the fluvial E and B sands, January and September 1986, respectively.

Hart, C. M. et a1., "Fracture Diagnostics Results for the First Multiwe11 Paludal Zone Stimulation," SPE Formation Evaluation, September 1987.

Institute of Gas Technology, Project 65056 Reports, "Sandstone Permeability and Porosity Measurements," July, August, October 1982.

Institute of Gas Technology, Project 65056 Report, "Special Dry Core Analysis of the Mesaverde Formation--U.S. DOE Multiwell Experiment, Garfield County, Colorado," submitted to DOE June 1984.

Institute of Gas Technology, Project 65056 Reports, "Sandstone Permeability and Porosity Measurements: Relative Permeability Data," October, November 1982 .

Institute of Gas Technology, Project 61071 Report, "Effects of Water and Stress Upon Permeability to Gas of Paludal and Coastal Sands-U.S. DOE Multiwell Experiment, Garfield County, Colorado," April 1985.

Institute of Gas Technology Project 65056 Reports, "Caprock Analysis," June, September 1982 .

Institute of Gas Technology Project 61071 Report, "Analysis of Stratigraphic Barriers, (Caprock) Between Sands in the Cretaceous Mesaverde Formation--U.S. Doe Multiwell Experiment, Garfield County, Colorado," June 1984.

Institute of Gas Technology, Project 61071 Report, "Directional Core Analysis of the Mesaverde Formation, U.S. DOE Multiwell Experiment, Garfield County, Colorado," September 1984.

Institute of Gas Technology Project 30568-02 Report, "Measurement and Analysis of Two-Phase Flow Through Low Permeability Media, 2 (Final Report)," March 1987.

Jones, F. O. and Owen, W. W., "A Laboratory Study in Low Permeability Gas Sands," J. Petroleum Technology, September 1980.

Kilmer, N. H. et al., "Pressure Sensitivity of Low Permeability Sandstones, "Journal of Petroleum Science and Engineering I, 1987.

Litton Core Research (Petrophysical Services/Core Laboratories) Report, "Gas Permeability of Sandstone Samples," Contract No. 04-4594, July 1986. 
Litton Core Research (Petrophysical Services/Core Laboratories) Report, 38B, "Gas Permeability of Fractured Whole Core and Matrix Plugs at Reservoir Pressures, "April 1987.

Litton Core Research (Core Laboratories) Report 308-87609, July 1987.

Lorenz, J. C., "Reservoir Sedimentology in Mesaverde Rocks at the Multiwel1 Experiment Site," SAND83-1078.UC 92, June 1983.

Lorenz, J. C., series of internal Sandia memos describing in detail the geology of the paludal, coastal and fluvial zones at the MWX site, January 1983, 1985, January 1986, respectively.

Lorenz, J. C. et al., "Fracture Characteristics and Reservoir Behavior of Stress Sensitive Fracture Systems in Flat-Lying Lenticular Formations," SPE/DOE/GRI 15224, Proceedings of Unconventional Gas Technology Symposium, Louisville, Kentucky, May 1986.

Lorenz, John C., "Reservoir Sedimentology of Mesaverde Rocks at the Multiwell Experiment Site and East Central Piceance Creek Basin," Sandia Report SAND87-0040.UC-92a, January 1987.

New Mexico Petroleum Research Recovery Center, New Mexico Institute of Mining and Technology, Project 2-75-7339 Reports for the Department of Energy's Morgantown Energy Technology Center, (Annual) 1985, 1986, 1987, 1988 (to be published) (First quarter) April 1988 (to be published).

Pitman, J. K. and Spencer, C. W., "Petrology of Selected Sandstones in the MWX Wells (northwest Colorado) and Its Relationship to Borehole Geophysical Log Analysis and Reservoir Quality," in "Geologic Studies in Support of the U.S. Department of Energy Multiwell Experiment, Garfield County, Colorado," C. W. Keighin and C. W. Spencer, eds., USGS Open File Report, 84-757, 1984.

Purce11, W. R., "Capillary Pressures--Their Measurement Using Mercury and the Calculation of Permeability Therefrom, "Petroleum Transaction, AIME, February 49.

Ren, N. K. and Hudson, P. J., "Predicting the In Situ Stress State Using Differential Wave Velocity Analysis," Proceedings of the 26th US Rock Mechanics Symposium on Rock Mechanics, Rapid City, South Dakota, June 1985.

Ren, N. K. and Roegiers, J. C., "Differential Strain Curve Analyses--A New Method for Determining the Preexisting In Situ Stress State From Rock Core Measurements," presented at the 5th ISRM Congress, Melbourne, April 1983.

RE/SPEC Data Reports, "Triaxial Compression and Brazillian Test Results for Samples From MWX 1, 2, and 3," RSI 0226 September 1982, RSI 0234 october 1982, RSI 0238 November 1982. 
RE/SPEC Inc. Progress Reports to Sandia National Laboratories, RSI(RCO)046/2-84/227, February 1984, RSI(RCO)-046/7-84/214, July, 1984 RSI (RCO) $-046 / 5-85 / 200$, May 1985 .

Rosepiler, J. M., "Calculation and Significance of Water Saturation in Low Porosity Shaly Gas Sands," Proceedings of SPWLA Twenty Second Annual Logging Symposium, June 23-26, 1981.

Sandia/CER Report Series, Written by the Multiwell Project Group at Sandia National Laboratories and CER Corporation, "Multiwell Experiment Final Report," 1. "The Marine Interval of the Mesaverde Formation," SAND870327.UC-92a, April 1987; 2. "The Paludal Interval of the Mesaverde Formation," to be published in 1988; 3 . "The Coastal Interval of the Mesaverde Formation," to be published in 1988, 4. "The Fluvial Interval of the Mesaverde Formation, "to be published in 1988.

Sattler, A. R., "The Multiwell Experiment Core Program," SPE/DOE 11763, Proceedings of the 1983 SPE/DOE Symposium on Low Permeability Gas Reservoirs, Denver, Colorado, March 1983.

Sattler, A. R. et al., Pressure Core Measurements in Tight Sandstone Lenses During the Multiwel1 Experiment, SPE/DOE/GRI 12853, Proceedings of the SPE/DOE/GRI Unconventional Gas Recovery Symposium, Pittsburgh, Pennsylvania, May 1984.

Sattler, A. R., "The Multiwel1 Experiment Core Program, II, "SPE/DOE/GRI 12584, ibid.

Sattler, A. R. et al., "Integration of Laboratory and Field Data for Insight on the Multiwell Experiment Paludal Stimulation," SPE/DOE 13891, Proceedings of the SPE/DOE 1985 Low Permeability Gas Reservoirs, Denver, Colorado, May 1985.

Senseny, P. E. and Pfeifle, T. W., "Fracture Toughness of Sandstones and Shales," Proceedings of the 25th Symposium in Rock Mechanics, Evanston, Illinois, June 1984.

Soeder, D. J. and Randolph, P. L., "Porosity Permeability and Permeability in Tight Mesaverde Sandstone, Piceance Basin, Colorado," SPE Formation Evaluation, June 1987.

Strickland, F. and Ren, N., "Predicting the In Situ Stress for Deep Wells Using the Differential Strain Curve Analyses," SPE 8954, Proceedings of the SPE/DOE Symposium on Unconventional Gas Recovery, Pittsburgh, Pennsylvania, May 1980 .

Strickland, F, and Ren, N., "Predicting the In Situ Stress for Deep Wells Using Differential Strain Curve Analysis," presented at the 31st Annual Tech. Meeting of the Pet. Soc. of CIM, Calgary, May 1980. 
Teufe1, L. W., "Determination of In Situ Stress From Anelastic Strain Recovery Measurements of Oriented Core," SPE/DOE 11649, Proceedings of 1983 SPE/DOE Joint Symposium on Low Permeability Gas Reservoirs, Denver, Colorado, March 1983.

Teufe1, L. W. and Warpinski, N. R., "Determination of In Situ Stress From Anelastic Strain Recovery Measurements of Oriented Core: Comparison to Hydraulic Fracture Stress Measurements," Proceedings of the 25th U.S. Symposium on Rock Mechanics, Northwestern University, Evanston, Illinois, June 1984.

Teufe1, L. W., "Determination of Hydraulic Fracture Aximuth by Geophysical, Geologic and Oriented-Core Methods at the Multiwell Experiment site, Rifle, Colorado," SPE 13226, 59th Annual SPE Technical Conference and Exhibition, Houston, Texas, September 1984.

Thorne, B. J. and Morris, H. E., "Advances in Borehole Seismic Fracture Diagnostics," SPE/DOE, 16405, SPE/DOE 16402, Proceedings of the 1987 SPE/DOE Joint Symposium on Low Permeability Reservoirs, Denver, Colorado, May 1987.

Walls, J. D. et al., "Effects of Pressure and Partial Water Saturation on Gas Permeability in Tight Sands," JPT, April 1982.

Walls, J. D., "Measurement of Fluid Salinity Effects on Tight Gas Sands With a Computer Controlled Parameter, "SPE 11092, 57th Annual SPE Technical Conference and Exhibition, New Orleans, September 1982.

Walls, J. D., "Tight Gas Sands-Permeability, Pore Structure and Clay," JPT November 1982 .

Walls, J. D. and Amaefule, J. O., "Capillary Pressure and Permeability Relationships in Tight Gas Sands," SPE/DOE 13879, Proceedings of the 1985 SPE/DOE Joint Symposium On Low Permeability Reservoirs, May 1985.

Ward (Buckley) J. S. and Morrow, N. R., "Capillary Pressures and Gas Relative Permeabilities of Low Permeability Sandstone," SPE Formation Evaluation, September 1987.

Wardlow, N. C. and Taylor, R. P., "Mercury Capillary Pressure Curves and Interpretation of Pore Structure and Capillary Behavior in Reservoir Rock," Bu11. Can. Pet. Geol., 24, 1976.

Warpinski, N. R. et al., "In Situ Stress Measurements at DOE's Multiwe11 Experiment Site, Mesaverde Group, Rifle, Colorado," JPT, March 1985.

Warpinski, N. R., et al., "Fracture and Testing Case Study of Paludal, Tight, Lenticular Gas Sands," SPE Formation Evaluation, Dec. 1977.

Warpinski, N. R. and Teufe1, L. W., "In Situ Stresses in Low Permeability, Nonmarine Rocks," Proceedings of the 1987 SPE/DOE Joint Symposium on Low Permeability Reservoirs, Denver, Colorado, SPE/DOE 16402, May 1987. 
Warpinski, N. R., "Determining the Minimum In Situ Stresses from Hydraulic Fracturing Through Perforations," Proceedings of the 2nd International Workshop on Hydraulic Fracture Stress Measurements, Minneapolis, Minnesota, June 1988.

Waxman, M. H. and Smits, L. J. M., "Electrical Conductivities in $0 i 1$ Bearing Shaly Sands," SPEJ, June 1968, in Petroleum Transactions, AIME, 1968.

Waxman, M. H. and Thomas, E. C., "Electrical Conductivities in Shaly Sands I. The Relation Between Hydrocarbon Saturation and Resistivity Index: II. The Temperature Coefficient of Electrical Conductivity, "JPT, February 1974, in Petroleum Transactions, AIME, 1974.

Wei, K. K. et al., "Effect of Fluid, Confining Pressure, and Temperature on Absolute Permeabilities of Low Permeability Sandstones, "SPE Formation Evaluation, August 1986.

Wellington, S. L. and Vinegar, H. J., "X-Ray Computerized Tomography," JPT, August 1987.

Western Atlas International (Core Laboratories) Report (Addition to Litton Core Laboratories) Report 308-87609, December 1987. 
DISTRIBUTION:

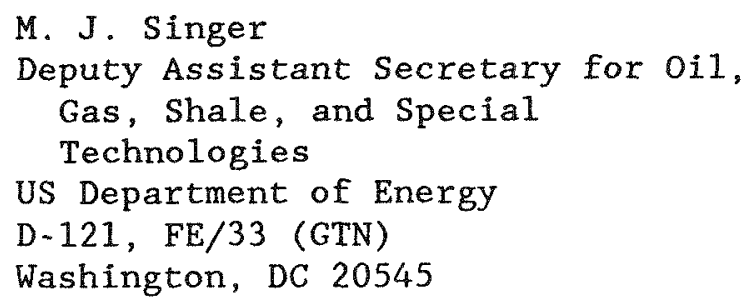

Los Alamos National Laboratory (3) Earth and Space Science Division Los Alamos, NM 87545

Attn:

$$
\begin{aligned}
& \text { C. W. Myers } \\
& \text { R. J. Hanold } \\
& \text { J. A. Albright }
\end{aligned}
$$

US Geological Survey (3)

Box 25046

Denver Federal Center

Denver, CO 80225

Attn: B. E. Law, MS 971
C. W. Spencer, MS 940
R. Johnson, MS 971

CER Corporation (30)

PO Box 94977

Las Vegas, NV 89193-4977

Attn: R. L. Mann (25)

F. R. Myal

P. T. Branagan

G. C. Kukal

W. H. Mathis

C. Cipolla

L. F. Elkins

2615 Oak Drive, \#28

Lakewood, CO 80215

J. L. Fitch

6034 Walnut Hill Circle

Dallas, TX 75230

Mobil Oil Corp. (2)

122517 th Street

Denver, CO, 80202

Attn: T. C. Vogt

T. Kirst

F. G. Martin

907 Glendell Drive

Irving, TX 75061

D. E. Nierode

Exxon Production Research Co. PO Box 2189

Houston, TX 77001

R. J. Saucier

Shell Western E\&P

Suite No. 7560

PO Box 576

Houston, TX 77001 
Mobil Research and Development

Corp. (4)

PO Box 819047

Dallas, TX 75381

Attn: M. Strubhar

L. Medlin

E. Sprunt

I. Abou-Sayed

R. W. Veatch

Amoco Production Co.

Research Department

PO Box 3385

Tulsa, OK 74102

Chandler \& Associates

Suite 1400

1860 Lincoln Street

Denver, CO 80203

Attn: R. Veghte

National Institute for Petroleum and

Energy Research (3)

PO Box 2128

Bartlesville, OK 74005

Attn: H, B, Carroll

C. J. Raible

B. L. Ga11

Smith Energy Services (2)

R. D. Timberline Building

Junction Hwys $58 \& 93$

Golden, CO 80403

Attn: D. Holcomb

W. Holcomb

L. Harrington

The Western Company

PO Box 186

Fort Worth, TX 76101

Dowell Schlumberger

Research Center (4)

PO Box 2710

Tulsa, OK 74101

Attn: J. Elbel

J. McClennan

B. Ainley

K. Nimerick
P. Warembourg

Dowel1 Schlumberger

PO Box 5818

Denver, CO 80217

M. Brugler

Western Atlas International

Core Laboratories

7304 E 38th Street

Tulsa, OK 74145

S. Leeds

Western Atlas International

Core Laboratories

10703 E. Bethany Drive

Aurora, CO 80014

Western Atlas International (4)

Core Laboratories

1300 East Rochelle Blvd.

Irving, TX 75062

Attn: J. Walls

R. Jenkins

$\mathrm{H}$. Hunt

E. York

P. Senseny

$\mathrm{RE} / \mathrm{SPEC}$, INC.

PO Box 725

Rapid City, SD 57701

United Nuclear Services (2)

PO Box 1569

Grand Junction, CO 81501

Attn: L. Fukui

R. Dayvault

Institute of Gas Technology (2)

3424 S. State Street

Chicago, IL 60616

Attn: P. L. Randolph

D. J. Soeder

Petroleum Recovery Research Center

(2)

NM Institute of Mining and

Technology

Socorro, NM 87801

Attn: F. D. Martin

N. R. Morrow 
Gas Research Institute (4) 8600 West Bryn Mawr Avenue Chicago, IL 60631

Attn: P. A. O'Shea

I. A. Salehi

C. F. Brandenberg

L. A. Rogers

S. A. Holditch

S. A. Holditch and Assoc. Inc. 900 Southwest Parkway East

College Station, TX 77840

C. Ossian

ARCO Oil \& Gas

PRC G118

Research \& Technical Services

2300 West Plano Parkway

Plano, TX 75075

B. McGlothlin

Chevron Geosciences Co.

PO Box 42832

Houston, TX 77242

T. L. Reeves

CNG Producing Co.

PO Box 2115

Tulsa, OK 74101-2115

B. Coffin

CNG Producing Company

Canal Place 1

Suite 3100

New Orleans, LA 70130-9990

D. Pellatz

Conoco Inc.

907 N. Poplar

Casper, WY 82601

D. Munson

David Munson Inc.

1525 Elm Street, Suite 1900

Dallas, TX 75201

M. Smith

NSI Technologies, Inc.

7030 Yale, Suite 502

Tulsa, OK 74136
J. Schwoebe1

Resource Enterprises, Inc.

400 Wakara Way

Salt Lake City, UT 84108

T. Juranek

Mobil Exploration and Producing U.S. Inc.

12450 Greenspoint Drive

Houston, TX 77060-1991

D. L. Luffel

ResTech Houston

14411 Cornerstone Village Drive

Houston, TX 77014

R. E. Barba

Schlumberger

1031 Andrews Highway

Midland, TX 79701

R. A. Plumb

Schlumberger-Doll Research

old Quarry Road

PO Box 307

Ridgefield, CT 06877

Shel1 Development Co. (3)

Bellaire Research Center

PO Box 481

Houston, TX 77001

Attn: D. C. Schultze

K. Hansen

J. Sh1yapobersky

M. Conway

Stim-Lab, Inc.

$3445 \mathrm{~N}$. Hwy 81

Duncan, OK 73534

G. R. Coulter

Sun Exploration and Production Company

Four NorthPark East

PO Box 2880

Dallas, TX 75221-2880

A. Jones

Terra Tek Inc.

420 Wakara Way

Salt Lake City, UT 84108 
Union Oil Co. of California (4)

Research Department

PO Box 76

Brea, CA 92621

Attn: C. Allen

J. Smith

J. Cameron

W. Minner

W. Stoner

Universal Well Services, Inc.

159 Northwood Dr.

Box 1456

Meadville, PA 16335

R. E. Wyman

Canadian Hunter Exploration, Ltd.

435 4th Avenue SW

Calgary, Alberta T2P 3 A 8

Canada

R. Kry

Esso Resources Canada Limited

Research Department

339 50th Avenue SE

Calgary, Alberta T2G 2B3

Canada

L. Roodhart

Shell Candada Ltd.

PO Box 2506

Calgary, Alberta T2P 356

Canada.

W. Hansen

Amoco Production Co.

1670 Broadway

Denver, CO 80202

S. Stone

Amoco Production Company

PO Box 800

Denver, CO 80201

D. 0. Cox

Angus Petroleum

350 Indiana, Ste \#600

Golden, CO 80401-5050
Barrett Energy Company (2)

1125 17th Street, Suite 2100

Denver, CO 80202

Attn: W. J. Barrett

K. Reinecke

J. N. Burkhalter

Burkhalter Engineering Inc.

715 Horizon Drive

Suite 330

Grand Junction, CO 81506

R. Martin

Coors Energy Company

PO Box 467

Golden, CO 80402

E. L. Sampson

Coseka Resources (USA) Ltd.

200 Writer Square

1512 Larimer Street

Denver, CO 80202-1602

Exxon Company USA (2)

PO Box 120

Denver, CO 80201

Attn: R. Moore

S. Barker

F. M. Moore

Pancanadian Petroleum Co.

60017 th Street, Suite 1800

Denver, CO 80202

W. H. Pease, Jr.

Willard Pease $0 i 1$ and Gas Company

PO Box 1874

Grand Junction, CO 81502

R. Poppe

Poppe Engineering

6066 E. Long Place

Englewood, CO 80112

T. Logan

Resource Enterprises

2516 Foresight Circle \#7

Grand Junction, CO 81505 
R. E. Chancellor

Rio Blanco Natural Gas Company

621 17th Street, Suite 1255

Denver, CO 80293

S. M. Struna

Tenneco Oil Company

PO Box 3249

Englewood, CO 80293

T. Barrett

Terred Oil Company

51817 th Street, Suite 770

Denver, CO 80202

J. D. Haley

Van Pollen and Haley, Inc.

5601 S. Broadway, Suite 400

Littleton, Co 80121

M. Krey

133 N. 8th Street

Grand Junction, CO 81505

J. A. More1

Consultant

2792 S. Fillmore Street

Denver, CO 80210

$R$. Hunter

Bureau of Land Management

Horizon Drive

Grand Junction, CO 81505

B. Kelso

Colorado Geological Survey

Department of Natural Resources

1313 Sherman Street Rm 715

Denver, CO 80203

Colorado Oil \& Gas Commission

1580 Logan Street, Suite 380

Denver, CO 80203

Petroleum Information Services

PO Box 2610

Denver, CO 80201-2612
J. W. Crafton

Petroleum Engineering Dept.

Colorado School of Mines

Golden, CO 80401

J. Johnson

Department of Geology

Mesa College

Grand Junction, CO 81501

A. H. Harvey

Petroleum Engineering Dept.

University of Missouri at Rolla

Rolla, MO 65401

R. Desbrandes

Petroleum Engineering Department

Louisiana State University

Baton Rouge, LA 70803-6417

Department of Geology (2)

University of New Mexico

Albuquerque, NM 87131

Attn: L. Crossey

R. Wright

C. T. Luiskutty

Engineering and Physics Dept.

Oral Roberts University

Tulsa, OK 74171

N. Tyler

Bureau of Economic Geology

University of Texas at Austin

Austin, TX 78713

C. G. Guffey

Texas Tech University

PO Box 4099

Lubbock, TX 79409

E. Rybicki

Mechanical Engineering Dept.

University of Tulsa

Tulsa, OK 74104

K. Aminian

West Virginia University

PO Box 6070, 213 White Hall

Morgantown, WV 26506 
D. Hambley

Argonne National Laboratory

EES-362, $9700 \mathrm{~S}$. Cass Avenue

Argonne, IL 60439

P. L. Archer

Battelle

505 King Avenue

Columbus, OH 43201

W. K. Overby

BDM Corporation

1199 Van Voorhis Road, Suite 4

Morgantown, WV 26505

V. A. Kuuskraa

ICF-Lewin Energy Division

9300 Lee Highway

Fairfax, VA 22031-1207

6000 D. L. Hartley

6010 D. E. Arvizu

6200 V. L. Dugan

6210 B. W. Marsha11

6213 D. Engi

6230 W. C. Luth

6232 W. R. Wawersik

6232 L. W. Teufel

6250 R. K. Traeger

6252 J. C. Dunn

6253 D. A. Northrop (30)

6253 J. C. Lorenz (5)

6253 A. R. Sattler (5)

6253 N. R. Warpinski (5)

6253 MWX File

6257 J. K. Linn

6258 P. J. Hommert

6258 B. J. Thorne

6258 H. E. Morris

6322 S. J. Finley

9114 C. A. Searls

3141 S. A. Landenberger (5)

3151 W. I. Klein (3)

3154-1 C. L. Ward (8) for DOE/OSTI

8524 J. R. Wackerly 